\title{
Quantifying Processing Map Uncertainties by Modeling the Hot-Compression Behavior of a Zr-2.5Nb Alloy
}

DOI:

10.1520/STP162220190031

\section{Document Version}

Accepted author manuscript

Link to publication record in Manchester Research Explorer

\section{Citation for published version (APA):}

Daniel, C. S., Jedrasiak, P., Peyton, C. J., Quinta Da Fonseca, J., Shercliff, H. R., Bradley, L., \& Honniball, P. D. (2021). Quantifying Processing Map Uncertainties by Modeling the Hot-Compression Behavior of a Zr-2.5Nb Alloy. In Zirconium in the Nuclear Industry: 19th International Symposium (pp. 93-122). [STP162220190031] ASTM International. https://doi.org/10.1520/STP162220190031

Published in:

Zirconium in the Nuclear Industry: 19th International Symposium

\section{Citing this paper}

Please note that where the full-text provided on Manchester Research Explorer is the Author Accepted Manuscript or Proof version this may differ from the final Published version. If citing, it is advised that you check and use the publisher's definitive version.

\section{General rights}

Copyright and moral rights for the publications made accessible in the Research Explorer are retained by the authors and/or other copyright owners and it is a condition of accessing publications that users recognise and abide by the legal requirements associated with these rights.

\section{Takedown policy}

If you believe that this document breaches copyright please refer to the University of Manchester's Takedown Procedures [http://man.ac.uk/04Y6Bo] or contact uml.scholarlycommunications@manchester.ac.uk providing relevant details, so we can investigate your claim.

\section{OPEN ACCESS}




\section{Fabrication and Alloy Development}



STP 1622, 2021 / available online at www.astm.org / doi: 10.1520/STP162220190031

Christopher S. Daniel, ${ }^{1}$ Patryk Jedrasiak, ${ }^{2}$ Christian J. Peyton, ${ }^{1}$ João Quinta da Fonseca, ${ }^{1}$ Hugh R. Shercliff, ${ }^{2}$ Luke Bradley, ${ }^{3}$ and Peter D. Honniball ${ }^{3}$

\title{
Quantifying Processing Map Uncertainties by Modeling the Hot-Compression Behavior of a $\mathrm{Zr}-2.5 \mathrm{Nb}$ Alloy
}

\section{Citation}

C. S. Daniel, P. Jedrasiak, C. J. Peyton, J. Quinta da Fonseca, H. R. Shercliff, L. Bradley, and P. D. Honniball, "Quantifying Processing Map Uncertainties by Modeling the Hot-Compression Behavior of a Zr-2.5Nb Alloy," in Zirconium in the Nuclear Industry: 19th International Symposium, ed. A. T. Motta and S. K. Yagnik (West Conshohocken, PA: ASTM International, 2021), 93-122. http://doi.org/10.1520/STP162220190031

\begin{abstract}
Compression dilatometer tests were used to study the hot deformation response of a zirconium ( $\mathrm{Zr}$ )-2.5\% niobium ( $\mathrm{Nb}$ ) alloy over the temperature range $650^{\circ} \mathrm{C}$ to $850^{\circ} \mathrm{C}$ and strain rates of $10^{-2.5} \mathrm{~s}^{-1}$ to $10^{+1} \mathrm{~s}^{-1}$. A high number of test conditions was used (72, with every test duplicated) in order to assess how differences in data processing influence the resulting relationships among flow stress, temperature, and strain rate. Particular attention was paid to processing maps, showing strain-rate sensitivity over the processing domain, commonly cited in the field and widely used as a basis to determine optimum processing conditions. Significant variations in these maps were found to depend on the number of data points included and the fitting procedure used to smooth the data. A finite element model of the test demonstrates the order of the corrections that
\end{abstract}

\footnotetext{
Manuscript received March 6, 2019; accepted for publication December 13, 2019.

${ }^{1}$ Centre for Light Alloy Research and Innovation, The University of Manchester, Oxford Road, Manchester, M13 9PL, UK C. S. D. http://orcid.org/0000-0002-5574-6833, C. J. P. http://orcid.org/0000-0002-7735-0151, J. Q. http://orcid.org/0000-0001-6063-8135

${ }^{2}$ Dept. of Engineering, University of Cambridge, Trumpington Street, Cambridge, CB2 1PZ, UK P. J. http://orcid.org/0000-0001-6321-4821, H. R. S. http://orcid.org/0000-0001-5950-8026 ${ }^{3}$ Rolls-Royce plc, Derby, DE21 7XX, UK P. D. H. http://orcid.org/0000-0001-5561-0832 ${ }^{4}$ ASTM 19th International Symposium on Zirconium in the Nuclear Industry on May 19-23, 2019 in Manchester, UK.
} 
can be required to the flow stress and the consequent processing maps due to friction at the platen-workpiece interface and nonuniform temperature and deformation in the test piece. Changes in crystallographic texture, measured using electron-backscatter diffraction, illustrate the effect of temperature, strain, and strain rate on the deformation, phase transformation, and recrystallization mechanisms. A significant spread in response arises as a result of variation in microtexture among samples and the tendency for flow to localize, giving rise to scatter in the measurements and generating artifacts in the processing map. Although the processing map methodology is strongly affected by experimental uncertainty, a detailed analysis of the final microstructures in the test samples shows similar features to those produced during industrial-scale processing, providing insight into the deformation mechanisms in dual-phase $\mathrm{Zr}$-Nb alloys.

\section{Keywords}

alpha beta processing, zirconium, compression testing, processing maps

\section{Introduction}

The specific thermomechanical processing route for zirconium $(\mathrm{Zr})$ alloys is chosen to control the development of microstructures and favored crystallographic orientations (textures), which greatly affect the mechanical properties of nuclear reactor components in service. ${ }^{1,2}$ For the use of stronger dual-phase zirconium-niobium (Zr-Nb) alloys in new nuclear applications, ${ }^{3}$ containing both $\alpha$ (hexagonal closepacked) and $\beta$ (body-centered-cubic) phases, a better understanding of the effect of processing parameters on two-phase microstructure and texture evolution during high-temperature deformation is required to minimize process development costs and for optimization of the processing route.

In an ideal process optimization study, the microstructure evolution would be studied by characterizing the material deformed under well-controlled process conditions. But because the stress-strain response of a material is affected by the constitutive behavior and microstructural evolution, it has been suggested that the stressstrain behavior alone could be used to determine the optimum processing conditions. This is the idea behind the processing map tool proposed by Prasad et al., which is based on the approach of dynamic materials modeling (DMM). ${ }^{4,5}$ In this approach, effective processing conditions are those that maximize the power dissipation term $\eta$, which describes the partitioning of deformation energy between dissipated heat and storage through microstructural changes in the material. ${ }^{6}$ The term $\eta$ is defined as $m /(1+m)$; therefore, maximizing $\eta$ is equivalent to maximizing the strain-rate sensitivity, $m$. Processing maps have been widely used to determine the optimum hot deformation regimes in all materials, including $\mathrm{Zr}$ alloys ${ }^{7-20}$ and titanium (Ti) alloys, ${ }^{21-26}$ in studies where observations of the final microstructures at room temperature are used to validate the process map. The processing map approach has become even more popular recently, with the wider availability of thermomechanical simulators such as the Gleeble and compression dilatometers, which significantly speed up compressive testing. These machines make it very easy 
to rapidly produce process maps and quickly assess new alloys for processability, which has led to an explosion in the number of process map studies for all kinds of alloys and composites.

Despite its popularity and wide acceptance, there are significant shortcomings with using the process map methodology to identify processing conditions. There has been strong criticism of the DMM approach underpinning the method. It has been called too simple to account for the complexity of the many deformation and microstructure evolution processes involved. ${ }^{6,27,28}$ Many recent articles avoid using the power dissipation term from the DMM approach and instead create processing maps using only strain-rate sensitivity values, which are almost equivalent. It is plausible that a high strain-rate sensitivity might identify deformation conditions where nonconservative mechanisms are active, involving grain and phase boundary movement, for example. ${ }^{13,16,20,29-33}$ However, obtaining strain-rate sensitivity variation using the methodology proposed is fraught with difficulties that are very often ignored or given only cursory attention. The method relies on data from hot uniaxial compression tests, during which the deformation conditions always vary across the sample in ways that depend on the details of the experimental setup. Although the data are often "corrected," 12,30 details of these corrections are often not given. Furthermore, the material tested often has large microstructural features of sizes comparable to those of the samples tested, ${ }^{12}$ which cause experimental scatter, but this is either ignored or not reported. One of the consequences is that although the processing map methodology is very popular, reproducibility is very poor. For example, the contour maps for a $\mathrm{Zr}-2.5 \mathrm{Nb}$ alloy in the low strain-rate regime $\left(10^{-3}\right.$ to $\left.10^{-2} \mathrm{~s}^{-1}\right)$ show many different maximum values for $m$ formed at either $710^{\circ} \mathrm{C}$ to $830^{\circ} \mathrm{C},{ }^{16} 730^{\circ} \mathrm{C},{ }^{16}$ $750^{\circ} \mathrm{C},{ }^{11} 770^{\circ} \mathrm{C}$ to $900^{\circ} \mathrm{C},{ }^{16} 900^{\circ} \mathrm{C},{ }^{11} 920^{\circ} \mathrm{C}$ to $1020^{\circ} \mathrm{C},{ }^{12}$ and $950^{\circ} \mathrm{C}{ }^{15}$

The aim of this study was to critically assess whether the processing map approach can be used to predict microstructural development in $\mathrm{Zr}-2.5 \mathrm{Nb}$ and to identify ideal process conditions. The process map methodology was used but with many more tests than is usual and repetitions at each condition. A finite element (FE) model of the tests was used to evaluate the effects of friction and thermal gradient and the resultant inhomogeneous deformation. This paper explores these factors and highlights the variations in outcome that can arise in interpreting flow stress data to develop process maps purely derived from differences in analysis method. It then tests processing map predictions by comparing the microstructures of samples deformed under different conditions.

\section{Compression Dilatometer Tests}

\section{STARTING MATERIAL}

The material studied was a $\mathrm{Zr}-2.5 \mathrm{Nb}$ alloy specially produced by the Wah Chang Corporation to obtain a small prior- $\beta$ grain size. This was achieved through forging of a 27-in.-diameter ingot into a 5-in.-thick slab, which was then hot-rolled to 3 in. thick and finally machined to a starting material block, shown in figure $1 \boldsymbol{A}$. 
FIG. 1 (A) Schematic of the starting forged block of Zr-2.5Nb material and

$(B)$ a machined compression cylinder, showing orientation of the sample compression ( $C D$ ) and radial ( $\mathrm{R} 1$ and $\mathrm{R} 2$ ) directions relative to the rolled plate.

The optical polarized light micrographs of the starting microstructure show

(C) packets of fine Widmanstätten $\boldsymbol{\alpha}$-laths, along with $(D)$ the outline of much larger prior- $\beta$ grains.
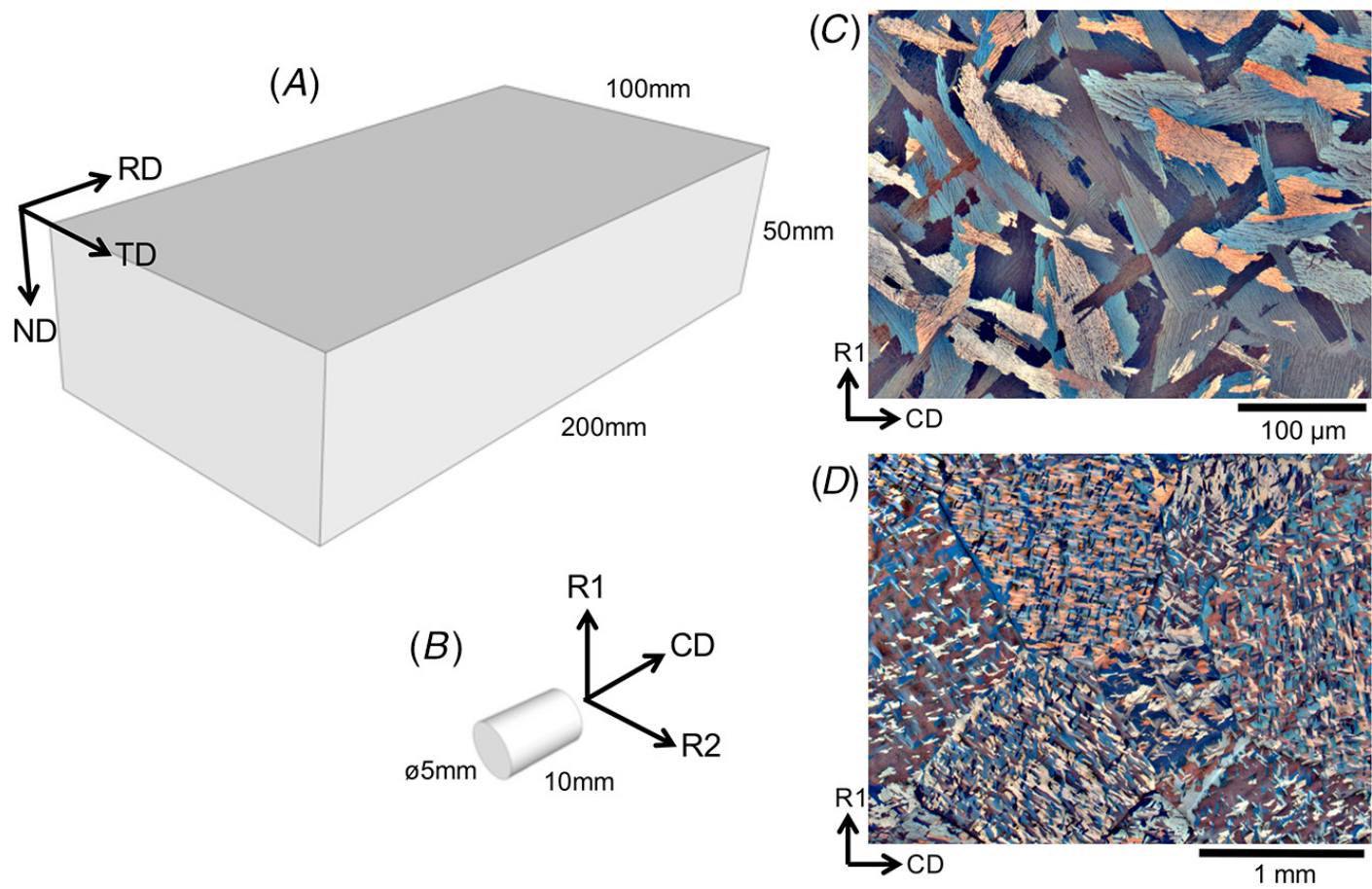

The $\beta$-transus in the starting $\mathrm{Zr}-2.5 \mathrm{Nb}$ material was recorded at $890^{\circ} \mathrm{C}$, which was determined by length changes measured on a DIL $805 \mathrm{~A} / \mathrm{D} / \mathrm{T}$ quenching and deformation dilatometer during an inductive heating cycle at $1.5^{\circ} \mathrm{C} / \mathrm{s}$. The initial forged microstructure was air-cooled from just above the $\beta$-transus, resulting in a microstructure of Widmanstätten packets of $\alpha$-laths, as shown in figure $1 C$ and $D$, separated by fine filaments of retained metastable $\beta_{\mathrm{zr}}{ }^{34}$ Analysis of the starting material shows prior- $\beta$ grains covering an average area of $0.59 \pm 0.04 \mathrm{~mm}^{2}$ with a diameter of $0.75 \pm 0.03 \mathrm{~mm}$, which are significantly smaller compared with previous hotdeformation studies on $\mathrm{Zr}-2.5 \mathrm{Nb} .{ }^{12}$

A number of cylindrical specimens measuring $10 \mathrm{~mm}$ in height and $5 \mathrm{~mm}$ in diameter were machined from the forged block, as shown schematically in figure $1 B$, with orientation relative to the plate. These were cut with a starting texture such that the $\alpha$-phase basal pole maxima was initially aligned parallel with the compression direction (CD) along the longitudinal axis of the sample, as shown in figure 2. A map of the indexed $\alpha$ orientations, as slices taken from cross sections of the sample, are shown in the radial $(\mathrm{R} 1, \mathrm{R} 2)$ plane and in the CD-R2 plane. Also shown are reconstructed maps of the larger $\beta$-grains formed at high temperature, which were determined using a $\beta$-phase reconstruction software developed by Davies et al. ${ }^{35-38}$ 
FIG. 2 Analysis of starting $\alpha$ and $\beta$ orientations within a compression sample. Pole figures, showing the texture measured over an area of $145 \mathrm{~mm}^{2}$ at a step size of $5 \mu \mathrm{m}$, are plotted for the $\alpha$-phase in $(A)$ and $\beta$-phase in (D) with respect to the subsequent compression ( $C D$ ) and radial (R1 and R2) directions. The orientation maps are shown as cross sections of a compression sample, with many fine Widmanstätten $\alpha$-laths in $(B)$ and $(C)$ and a number of larger $\beta$-grains appearing at high temperature in $(E)$ and $(F)$, which were reconstructed using a software algorithm.

(A)
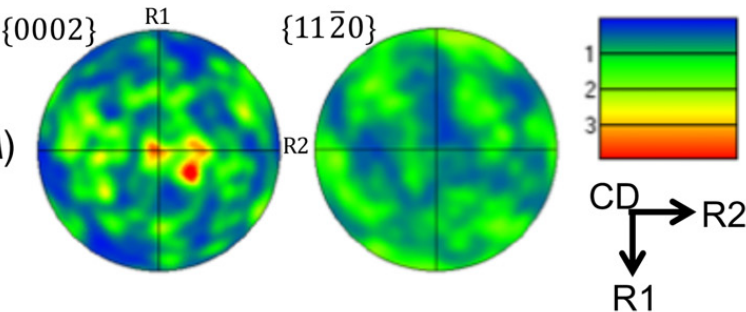

$(B)$

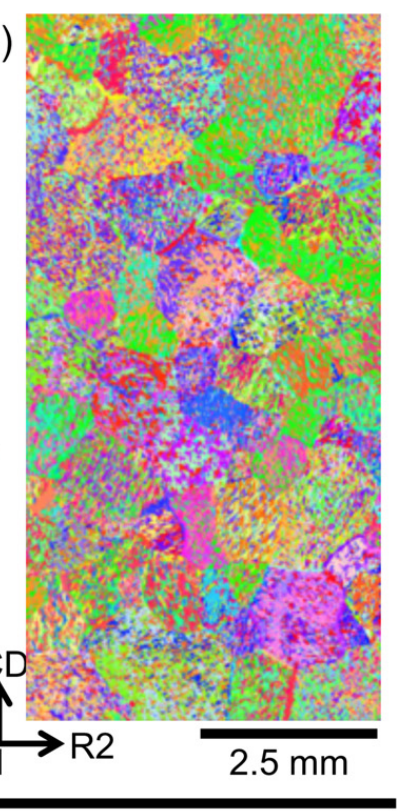

\section{(C)}
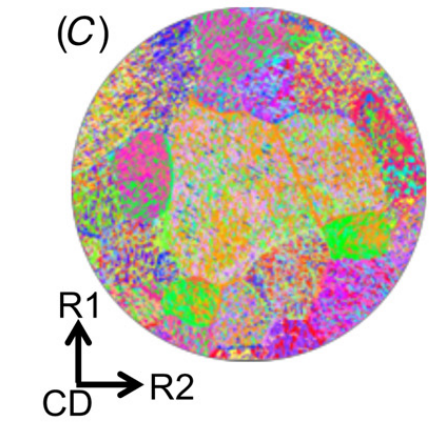

a-phase
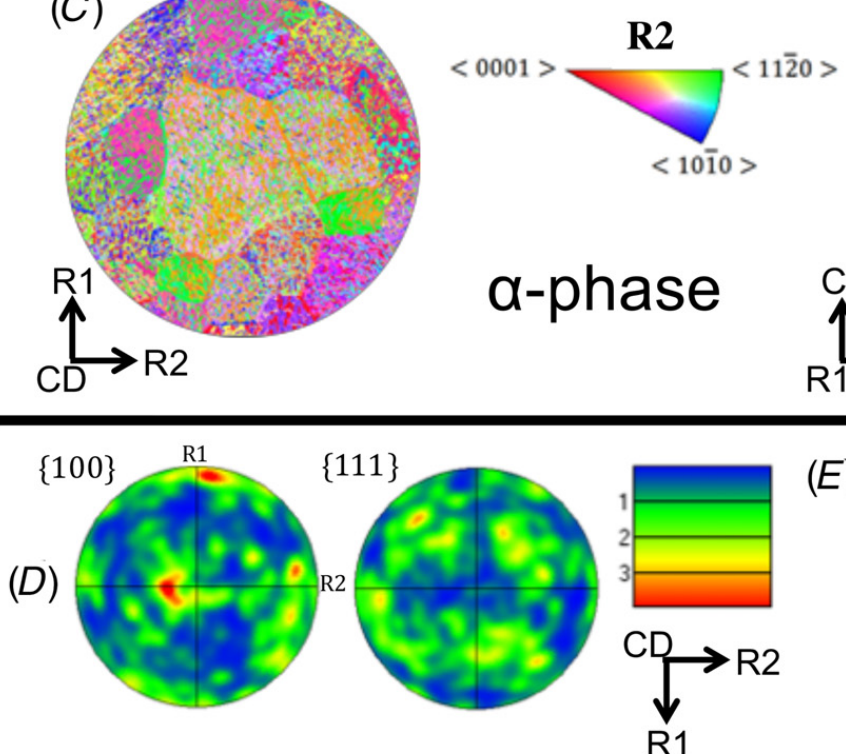

$(E)$
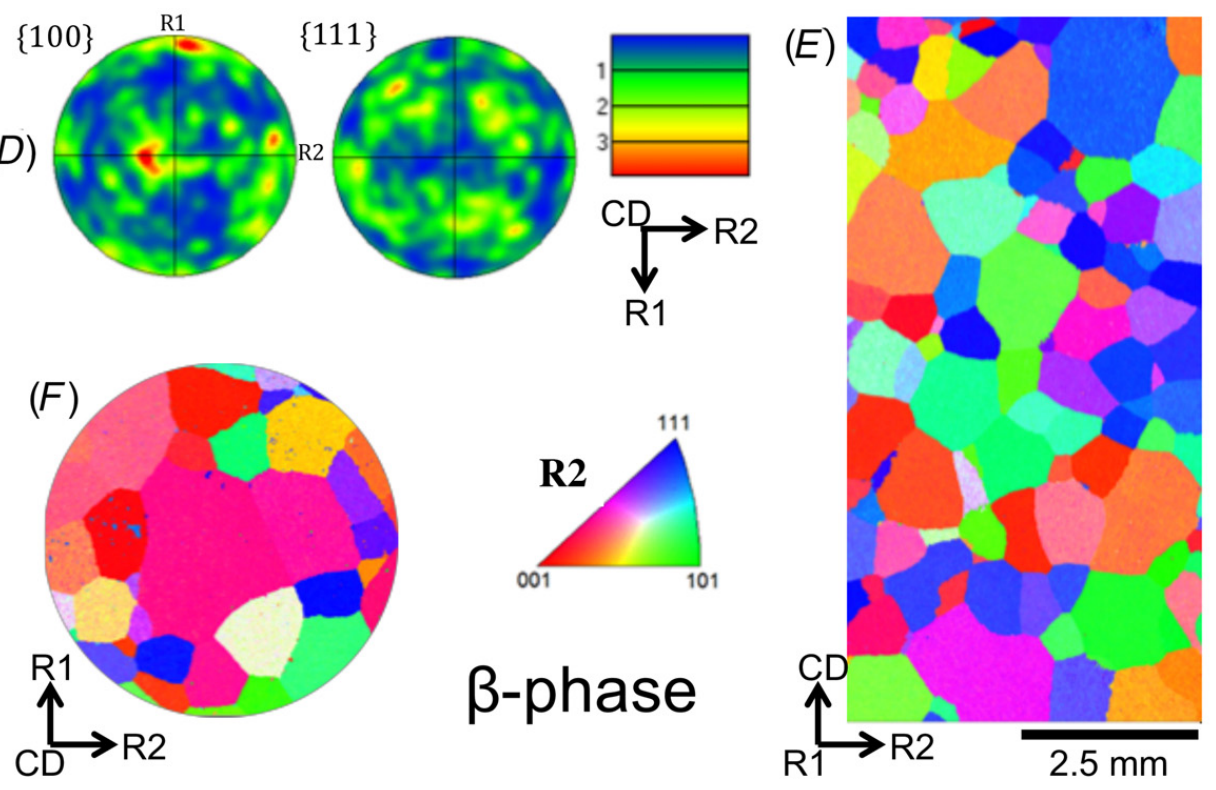

$\beta$-phase

\section{HOT-COMPRESSION TESTING}

Compression tests were carried out using a TA Instruments DIL 805 A/D/T quenching and deformation dilatometer. A disadvantage of other high-temperature compression rigs is that a furnace is usually used to heat samples, which is time 
consuming and expensive. Temperature on the dilatometer is instead controlled through induction heating of samples, which has the advantage of providing fast heating and cooling rates, with minimum sample changeover time between tests, for quick investigation of a large hot-compression matrix.

Test temperatures were chosen to cover the range over which the $\alpha / \beta$ volume fraction changes with temperature. ${ }^{39}$ Temperature was monitored using an S-type thermocouple, welded at mid length on each specimen. Compression tests were conducted at temperatures, $T$, of $650,675,700,725,750,775,800,825$, and $850^{\circ} \mathrm{C}$. Tests were conducted in an inert helium $(\mathrm{He})$ gas atmosphere to minimize sample oxidation. The specimens were heated to the deformation temperature at $5^{\circ} \mathrm{C} / \mathrm{s}$ and held for $3 \mathrm{~min}$ to homogenize the temperature. At each temperature, tests were conducted at a constant strain rate, $\dot{\varepsilon}$, of $10^{-2.5}, 10^{-2}, 10^{-1.5}, 10^{-1}, 10^{-0.5}, 10^{+0}, 10^{+0.5}$, and $10^{+1} \mathrm{~s}^{-1}$ to a true strain, $\varepsilon$, of 0.69 (corresponding to $50 \%$ height reduction). Tests were also repeated at each condition. In order to minimize frictional stresses generated during deformation, a graphite and nickel lubricant was applied between the specimen and the silicon nitride $\left(\mathrm{Si}_{3} \mathrm{~N}_{4}\right)$ compression platens. Heat loss to the silicon nitride platens was found to contribute to a $50^{\circ} \mathrm{C}$ to $100^{\circ} \mathrm{C}$ temperature difference from the edge to the center of the compression sample. Immediately after the hot-compression test, specimens were cooled at a rate of $5^{\circ} \mathrm{C} / \mathrm{s}$ and the recorded data converted to true stress and true strain plots.

\section{DATA REPOSITORY}

All experimental data are available from the Zenodo repository, along with an accompanying python script to generate the plots. ${ }^{40}$

\section{TRUE STRESS-STRAIN RESPONSE}

The convention in compression testing is to convert the measured forcedisplacement response to a true stress-strain response, assuming homogeneous frictionless deformation:

$$
\sigma_{\text {true }}=\frac{F}{\pi D^{2}} \quad \text { and } \quad \varepsilon_{\text {true }}=\ln \frac{H}{H_{0}}
$$

The instantaneous diameter, $D$, is calculated from the height, $H$, the original diameter, $D_{0}$, and the original height, $H_{0}$, using volume conservation. Figure $3 A$ and $B$ shows the idealized shape change assumed in equation (1); in contrast, figure $3 C$ shows a predicted sample shape with barreling due to friction and a nonuniform temperature. It is still convenient to convert the force-displacement data using equation (1), using a notional average diameter as calculated as usual, for example, to compare test data FE predictions and published constitutive data. Test data presented in this way will be referred to as notional true stress-strain curves, to distinguish between these and a corrected constitutive response. Figure $4 A$ shows a sample of measured forcedisplacement curves at a constant temperature for various strain rates and the corresponding true stress $(\sigma)$ versus true strain $(\varepsilon)$ responses. 
FIG. 3 Sample shapes in hot compression: $(A)$ initial, $(B)$ idealized homogeneous and frictionless, and $(C)$ predicted shape, showing barreling due to friction and temperature gradient.

$(A)$

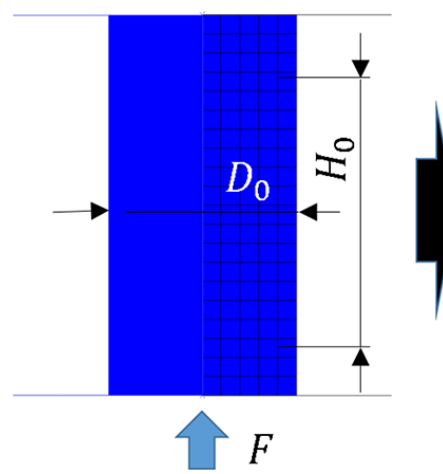

(B)

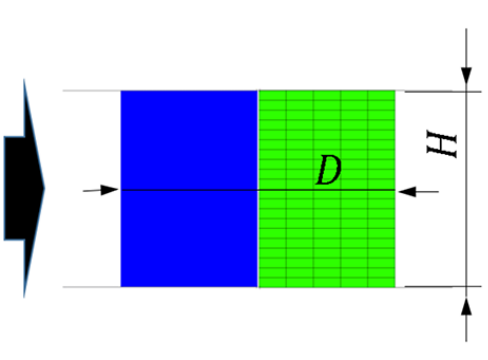

$(C)$

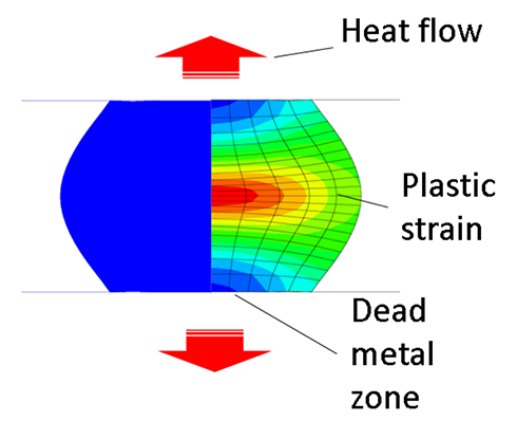

The experimentally measured true stress-true strain responses are shown in figure $4 B$ and $C$, demonstrating the effect of different temperatures at constant strain rate $\left(10^{-2.5} \mathrm{~s}^{-1}\right)$ and different strain rates at constant temperature $\left(800^{\circ} \mathrm{C}\right)$, with the complete data set available in the repository. ${ }^{40}$ The yield strength shows a clear trend with strain rate and temperature, with higher material strength at low temperatures and high applied strain rates. Following peak stress, the curves indicate that the material undergoes flow softening. All curves exhibit flow softening to a degree, although the amount varies with temperature, as well as with strain rate. The largest reduction in flow stress is recorded at $650^{\circ} \mathrm{C}$. Continuous apparent flow softening always appears at higher strain rates $\left(\dot{\varepsilon}>10^{+0} \mathrm{~s}^{-1}\right)$, along with flow softening exhibited in all tests at temperatures up to $800^{\circ} \mathrm{C}$ up to the largest strain increment $(\varepsilon=0.69)$. Near steady-state behavior is only reached in the majority of tests at $825^{\circ} \mathrm{C}$ and $850^{\circ} \mathrm{C}$. These characteristics of flow softening are commonly observed during deformation in the $\alpha+\beta$ regime of $\mathrm{Zr}$ and Ti alloys with starting lamellar microstructure. ${ }^{12,15,16,24,30,31}$

The repeatability in most cases is very good, with variation between duplicates of the order of $5 \%$ to $10 \%$, which may reflect real microstructural variation rather than experimental variability. The flow behavior is mostly reproduced in the majority of repeat tests, although there are noticeable differences in the flow stresses at some conditions. The uncertainty is greatest at low temperatures and high strain rates, when the flow curves exhibit some sharp variations in stress over time. Although the majority of raw data show relatively smooth flow stress behavior, a few tests at lower strain rates also showed occasional sharp drops in stress. Even at the highest temperatures, when the flow curves appear smooth and closely replicated, differences of around $5 \mathrm{MPa}$ exist between samples. Therefore, for the purposes of fitting an average response, two flow stress data points were extracted for analysis at a given strain in each given test. 
FIG. 4 (A) Sample force-displacement responses and corresponding notional true stress-strain responses at a range of different strain rates at $750^{\circ} \mathrm{C}$. The effect of (B) different temperatures, $T$, at a strain rate of $10^{-2.5} \mathrm{~S}^{-1}$ and $(C)$ different strain rates, $\dot{\varepsilon}$, at a temperature of $800^{\circ} \mathrm{C}$ on the measured notional true stress-strain responses represents a sample of the flow stress data for $\mathrm{Zr}$-2.5Nb in uniaxial compression recorded using the dilatometer.

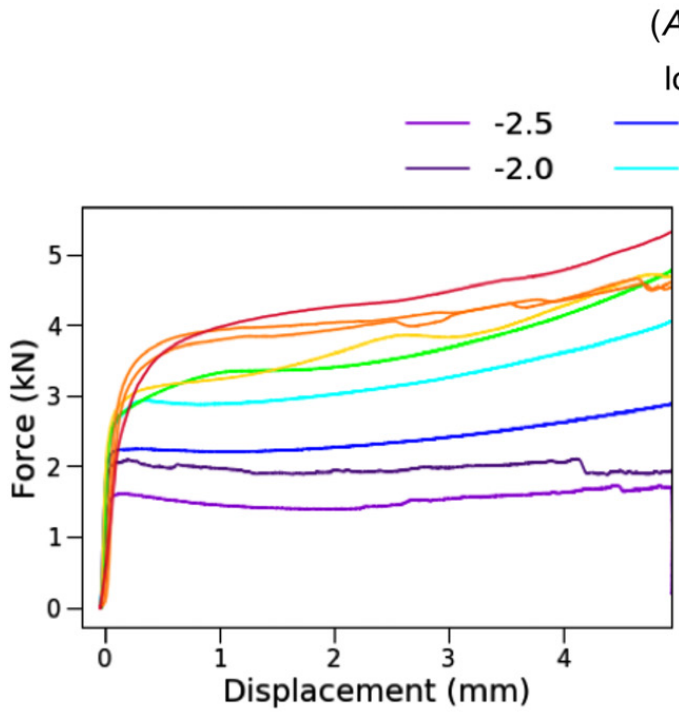

(B) $\dot{\varepsilon}=10^{-2.5} \mathrm{~s}^{-1}$

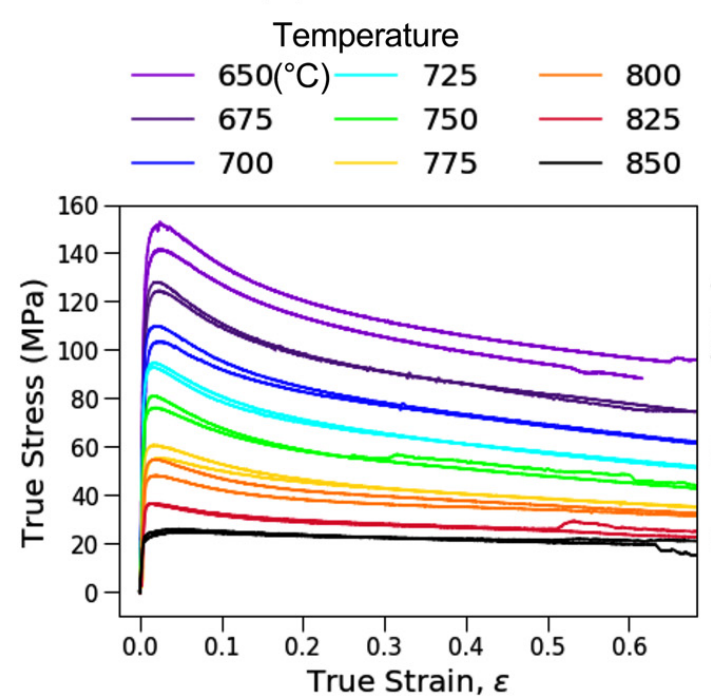

(A) $\mathrm{T}=750^{\circ} \mathrm{C}$ $\log$ (strain rate)

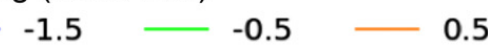

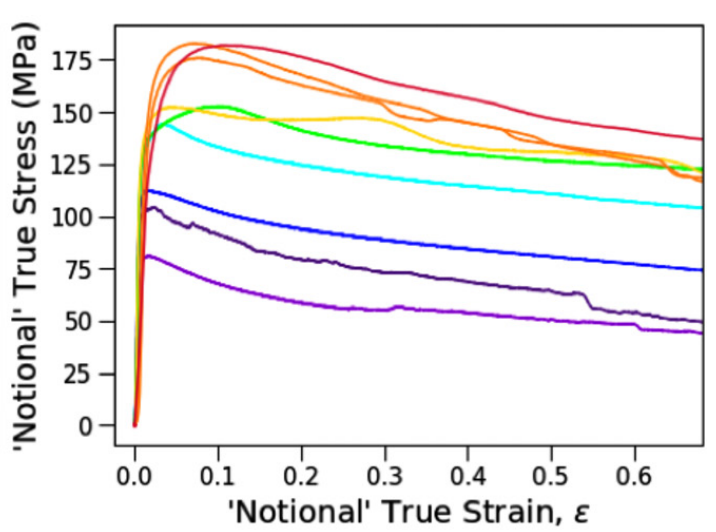

(C) $\mathrm{T}=800^{\circ} \mathrm{C}$ $\log$ (strain rate)

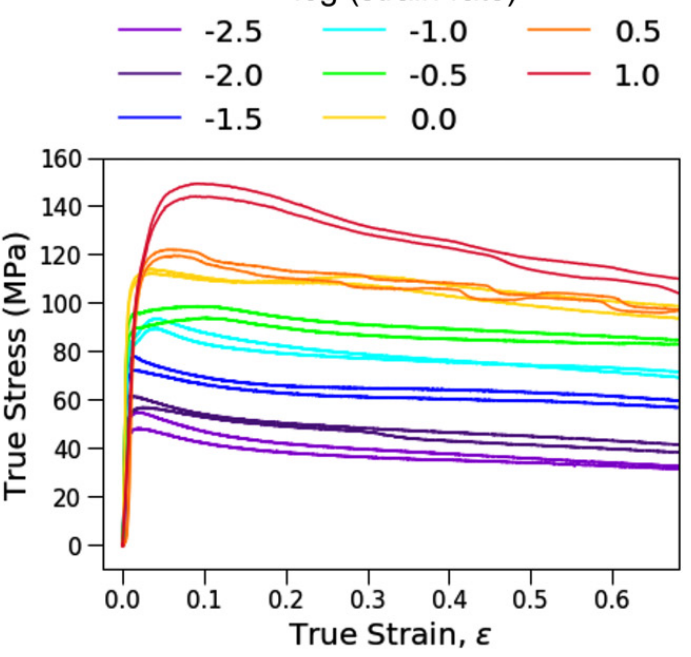
0.5 
Macrotexture measurements of the selected regions, before and after deformation, were performed using electron backscatter diffraction (EBSD) on the FEI CamScan MX2000 field emission gun scanning electron microscope and TESCAN MIRA3 field emission gun scanning electron microscope. EBSD data were collected at an operating voltage of $20 \mathrm{kV}$ with a working distance of $27 \mathrm{~mm}$ for the CamScan and $20 \mathrm{~mm}$ for the TESCAN. Both systems are equipped with AZtecHKL EBSD systems for pattern indexing, with subsequent analysis performed using Channel 5 software.

For the initial measurement of the starting forged material texture, a $5 \mu \mathrm{m}$ step size was chosen and a total area of $145 \mathrm{~mm}^{2}$ was analyzed. Following compression, macrotexture maps of the deformed samples were also recorded at a step size of $5 \mu \mathrm{m}$, over the entire surface parallel to the compression axis, in the R1-CD plane. Texture changes were measured both across the entire specimen and located within a deformed band at the center, covering a rectangular area of about 5 by $1 \mathrm{~mm}$. Fine microstructure orientation maps were also recorded at the center of samples following deformation at different strain rates of $10^{+0} \mathrm{~s}^{-1}$ and $10^{-2.5} \mathrm{~s}^{-1}$ at $800^{\circ} \mathrm{C}$, using a step size of $0.25 \mu \mathrm{m}$ to index both the $\alpha$ and $\beta$ phases and to investigate the differences in grain structure.

The images of compression samples deformed at $700^{\circ} \mathrm{C}, 800^{\circ} \mathrm{C}$, and $850^{\circ} \mathrm{C}$ at strain rates of $10^{+0} \mathrm{~s}^{-1}$ and $10^{-2.5} \mathrm{~s}^{-1}$ are shown in figure 5. The microstructures show clear evidence of nonuniform straining, with undeformed material in the form of dead metal zones (DMZs) at the top and bottom of the sample, retaining the large prior- $\beta$ grain structures from the starting material. Heavily deformed regions localize at the center. The different combinations of deformation parameters (temperature and strain rate) contribute to the extent of nonuniform strain gradients, affecting flow localization at the center and barreling of the edges. Flow localization at the center appears to increase at higher deforming temperatures, at $800^{\circ} \mathrm{C}$ and $850^{\circ} \mathrm{C}$, leading to extensive breakdown of the starting prior- $\beta$ grain structures, which is also most significant at lower strain rates of $10^{-2.5} \mathrm{~s}^{-1}$. At $700^{\circ} \mathrm{C}$, and at both $10^{+0} \mathrm{~s}^{-1}$ and $10^{-2.5} \mathrm{~s}^{-1}$, the sample center contains larger individual prior- $\beta$ grains that are less deformed, suggesting a more homogenous strain gradient and less localization. Throughout the samples, the dependence of the macroscale deformation on interaction of large prior- $\beta$ grain regions, along with strain localization at grain boundaries, is evident. In some cases, whole prior- $\beta$ grain regions are seen to slide out from the barreled surface. This is most clearly seen at the top right of the specimens in figure $5 C$ as well as in the bottom right of figure $5 D$.

The strain gradient in the sample is reflected in the variation of the $\alpha$ crystallographic orientation across the sample, as shown after deformation at $850^{\circ} \mathrm{C}$ and $10^{-2.5} \mathrm{~s}^{-1}$ in figure $5 E$. In the DMZs, each prior- $\beta$ grain retains the different $\alpha$ variant orientations. However, at the center, in the region of localized flow, the $\alpha$ orientations develop a weak texture, aligning the $\langle 11 \overline{2} 0\rangle$ parallel to CD and forming the 0002 basal pole with maxima in R1 and R2, along with a spread throughout the radial plane. 
FIG. 5 Optical polarized light micrographs of the Zr-2.5Nb compression samples after deformation at different temperatures and strain rates of $(A) 700^{\circ} \mathrm{C}, 10^{+0} \mathrm{~s}^{-1}$;

(B) $800^{\circ} \mathrm{C}, 10^{-2.5} \mathrm{~S}^{-1}$; (C) $800^{\circ} \mathrm{C}, 10^{+0} \mathrm{~s}^{-1}$; and (D) $850^{\circ} \mathrm{C}, 10^{-2.5} \mathrm{~S}^{-1}$. The extent of flow localization and barreling is seen to increase with increasing temperature and decreasing strain rate. An $\boldsymbol{\alpha}$-phase orientation map shows dead metal zones (DMZs) at the top and bottom of the sample after deformation at $850^{\circ} \mathrm{C}$, $10^{-2.5} \mathrm{~S}^{-1}$ in $(E)$, along with crystallographic texture changes observed in the central deformed region.

(A) $700^{\circ} \mathrm{C}, 10^{+0} \mathrm{~s}^{-1}$

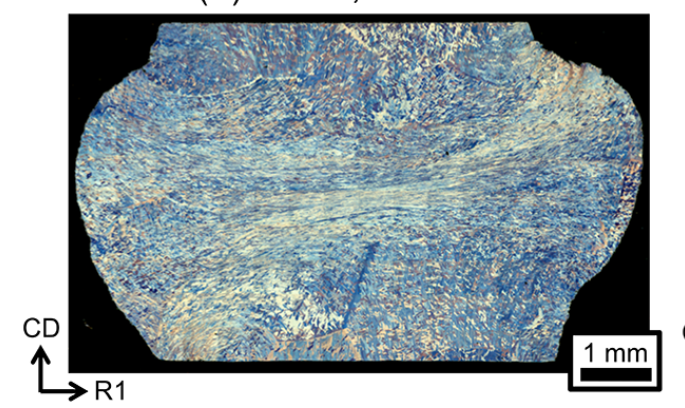

Dead metal zones (DMZs)

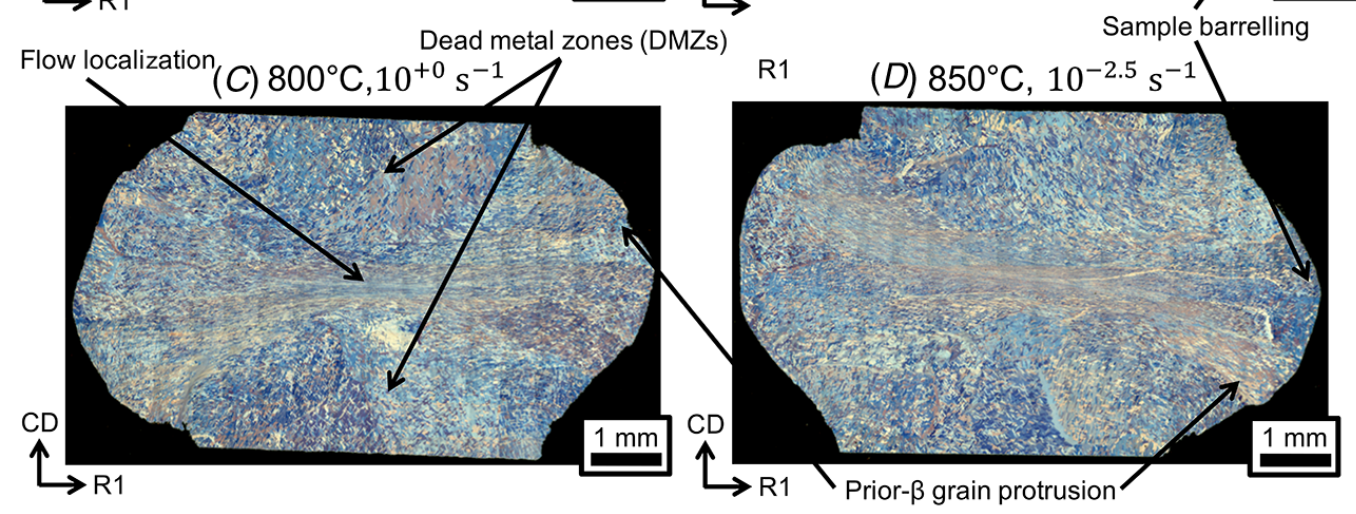

$850^{\circ} \mathrm{C}$

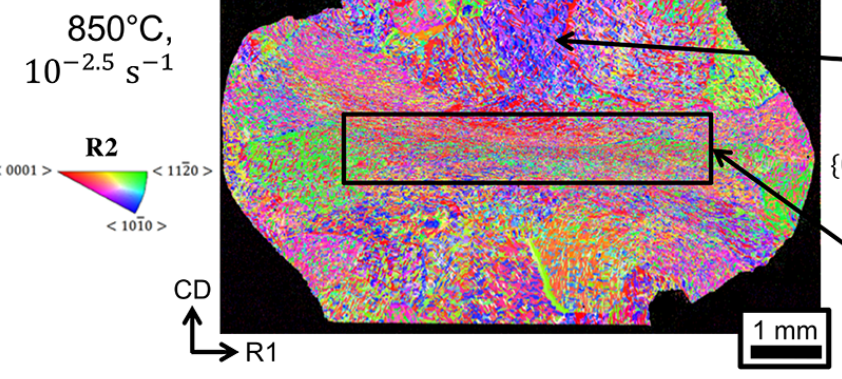

(B) $800^{\circ} \mathrm{C}, 10^{-2.5} \mathrm{~s}^{-1}$

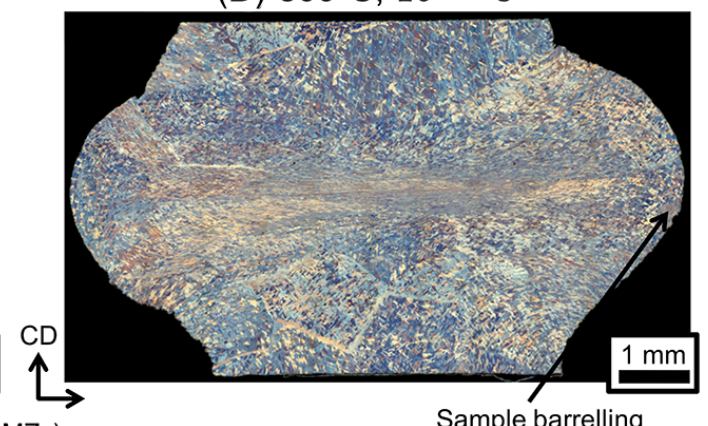

R1

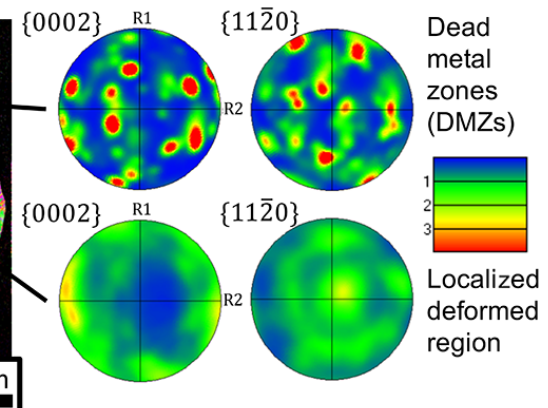

\section{Finite Element Modeling of Hot-Compression}

\section{Tests}

Finite element analysis was used to assess the influence of inhomogeneous deformation in the dilatometer tests, in particular the apparent shift in true stress-strain behavior due to friction at the platens, and a temperature gradient due to heat loss to the platens. Capturing the nonuniform temperature field requires a full heat transfer analysis of the dilatometer rig. This is challenging because the control 
system includes both induction heating and forced inert gas cooling to manage the sample temperature, and heat losses occur into the loading platens, while plastic dissipation adds a further nonuniform internal heat source. Furthermore, a single central thermocouple does not provide sufficient information to calibrate the heat transfer conditions between the sample and the platens. This study therefore involved a parametric investigation of the effect of friction and temperature gradient, using simplified boundary conditions.

\section{MODELING METHODOLOGY}

A numerical scheme was developed for inferring the uniaxial true stress-strain response by applying a systematic correction to the notional true stress-strain response taken directly from the test data, accounting for the influence of friction and inhomogeneous temperature. The procedure is illustrated in figure 6 and is summarized as follows:

(a) Take a first estimate for the constitutive response, $\sigma=f(T, \dot{\varepsilon}, \varepsilon)$, as input to the FE analysis, predicting the force displacement for the test matrix, and converting to notional true stress-strain (as for the experimental response, using equation [1]).

(b) At a number of discrete strains, evaluate the offset in stress, $\Delta \sigma=f(T, \dot{\varepsilon})$, caused by friction and a temperature gradient.

(c) Subtract this $\Delta \sigma$ from the experimental notional true stress-strain data, to give a corrected input data set for $\sigma=f(T, \dot{\varepsilon}, \varepsilon)$, and use this to repredict the experimental curves (in the form of notional true stress strain) to validate the corrected constitutive data.

\section{FE MESH AND THERMAL BOUNDARY CONDITIONS}

The axisymmetric mesh and initial dimensions are shown in figure 7, along with the idealized temperature boundary conditions. The temperature gradient was not measured in situ for the $\mathrm{Zr}-2.5 \mathrm{Nb}$ alloy. Nevertheless, similar tests using a Ti-6Al-4V alloy, under similar conditions using the same dilatometer, indicate peak gradients of the order $50^{\circ} \mathrm{C}$ to $100^{\circ} \mathrm{C}$, which reduce during the test as the sample shortens. It is reasonable to expect a similar temperature gradient to appear in the $\mathrm{Zr}-2.5 \mathrm{Nb}$ alloy because it is mostly affected by heat conduction to the loading platens, and $\mathrm{Zr}-2.5 \mathrm{Nb}$ has a similar thermal conductivity to Ti-6Al-4V $(17.1 \mathrm{~W} / \mathrm{mK}$ compared with $7.1 \mathrm{~W} / \mathrm{mK}$ ). The central temperature is well-maintained by the dilatometer, up to strain rates around $1 \mathrm{~s}^{-1}$, above which adiabatic heating by plastic dissipation leads to a rise in the central temperature. In the current work, in the absence of temperature data from the $\mathrm{Zr}-2.5 \mathrm{Nb}$ instrumented tests, a gradient was maintained from the nominal test temperature at the center of the sample to a fixed temperature below nominal at the platen interface.

Friction is difficult to measure so a constant friction coefficient was applied in the model and treated as an adjustable parameter. It is found that beyond a value of $\mu \approx 0.5$, the radial spread at the platen is small, and there is little sensitivity to the value of $\mu$. A sensitivity analysis was conducted to explore the influence of friction 
FIG. 6 Methodology for correcting the true stress-strain response using the FE model: (A) taking an initial $\sigma=f(T, \dot{\varepsilon}, \varepsilon)$ from the notional experimental data as input and determining a correction $\Delta \sigma(T, \dot{\varepsilon})$ from the FE output; $(B)$ applying correction $\Delta \sigma(T, \dot{\varepsilon})$ to the experimental data; and (C) validating the corrected FE input by matching the FE prediction with the experiment. FE modeling of true stressstrain curves for two temperature/strain rate combinations: $(D)$ and $(E) 700^{\circ} \mathrm{C}$, $10^{+0.5} \mathrm{~S}^{-1}$ and $(F)$ and $(G) 800^{\circ} \mathrm{C}, 10^{+0.5} \mathrm{~s}^{-1}$, show the initial input from the experiment (solid red), the resulting output (solid blue), the corrected input (dashed red), and the resulting corrected output (dashed blue) responses. The offset, $\Delta \sigma$, indicated by the black arrows, is seen to vary with strain at the different conditions.

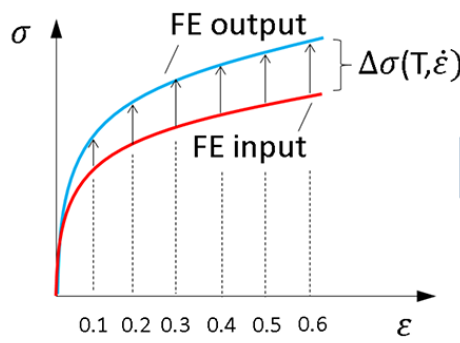

$(A)$

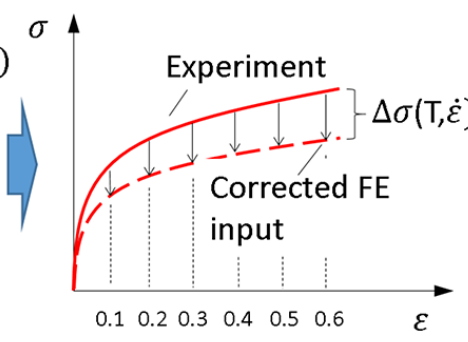

(B)

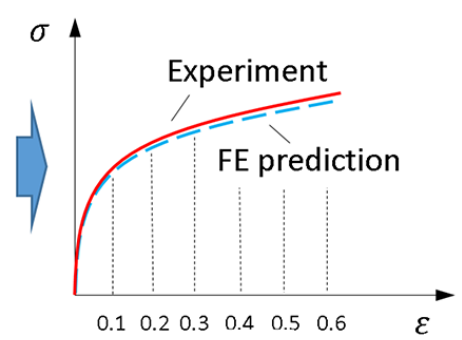

(C)
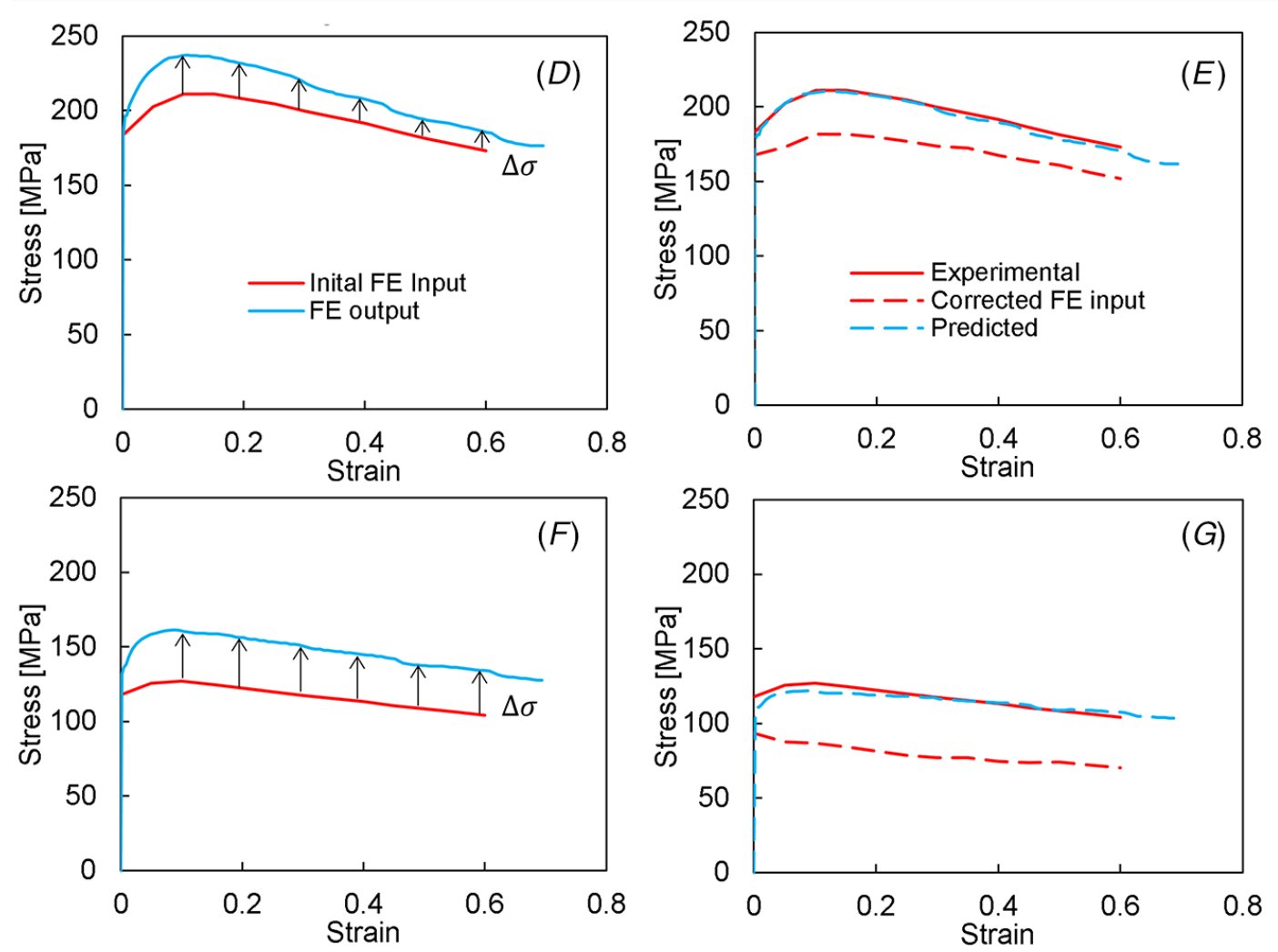

and the imposed temperature difference, with the final sample shape providing a qualitative comparator with the experiments (as in fig. 5). This analysis included the usual checks on mesh sensitivity and convergence, and details are available 
FIG. 7 FE model, showing the axisymmetric mesh, geometry, and boundary conditions. The compressive force is defined by $F$, and the friction force is defined by the product of the friction coefficient, $\mu$, and the pressure, $p$. The temperature gradient is defined by a nominal temperature at the center, $T_{\text {nominal, }}$ and the temperature drop, $\Delta T$.

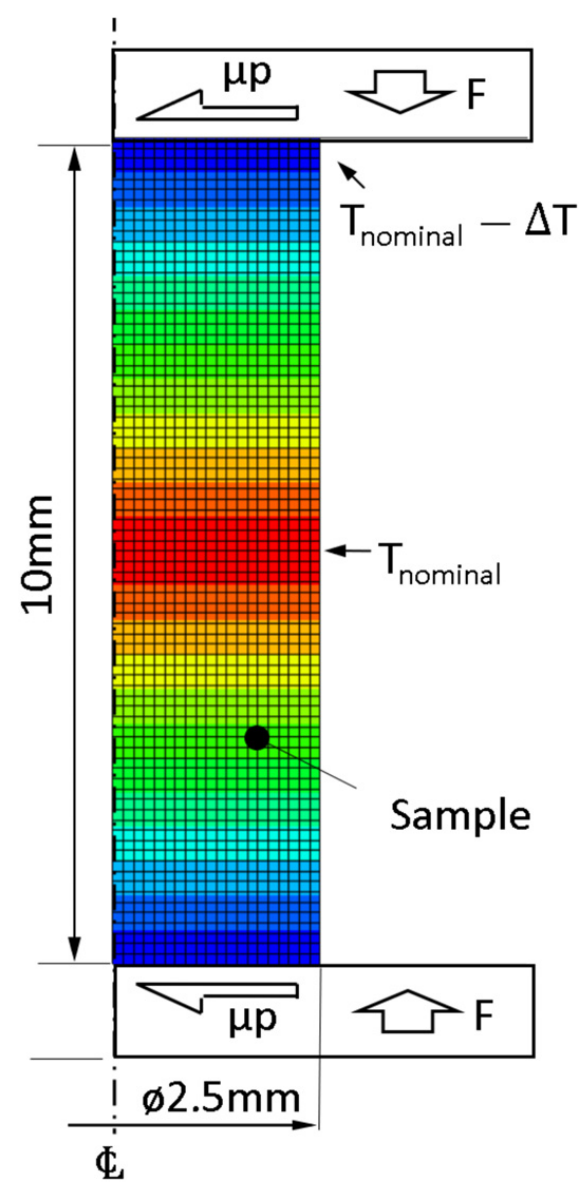

elsewhere. ${ }^{41}$ The results presented in this paper apply a friction coefficient $\mu=0.5$, and a temperature difference of $100^{\circ} \mathrm{C}$, which represent a worst-case upper bound, as a proof of concept.

\section{CONSTITUTIVE DATA}

The methodology addresses something of a circular problem-correcting the stressstrain response requires a reasonable first estimate of the constitutive response-to use as an input to the FE analysis. Options for this first estimate are: (a) true stressstrain constitutive response from the literature, if available and reliable, and (b) a data set for $\sigma=f(T, \dot{\varepsilon}, \varepsilon)$ that is extracted from the experimental data. Because the objective is to find the offset in the data $\Delta \sigma=f(T, \dot{\varepsilon}, \varepsilon)$, due to friction and a temperature gradient, it is reasonable to assume that this correction will be insensitive to the absolute values used as input, provided the flow stress and its variation $\sigma=$ $f(T, \dot{\varepsilon}, \varepsilon)$ cover the same processing domain as the experiments. 
An isotropic plastic response for the $\mathrm{Zr}-2.5 \mathrm{Nb}$ alloy was assumed, in spite of its strong texture and complex phase transformations, as the goal is to capture the firstorder effects of friction and temperature gradient. Hence, an isotropic average constitutive response is sufficient. The initial FE analysis used a perfectly plastic (strain-independent) fit to the raw data at a low strain $\varepsilon=0.05$. This implementation was used for setting up the FE model as outlined previously (e.g., for checks on convergence and mesh size and the sensitivity analysis on friction and temperature gradient ${ }^{41}$ ).

For the full analysis of the correction to flow stress, it was preferable to avoid loss of detail by curve-fitting directly to the experimental data before they had been compensated for inhomogeneity in deformation. The analysis therefore reverted to a full look-up table for flow stress $\sigma=f(T, \dot{\varepsilon}, \varepsilon)$, using the notional true stressstrain curves directly, rather than a perfectly plastic response. This still required judicious smoothing of the experimental data (to avoid introducing artifacts in the data, such as local nonphysical fluctuations in strain-rate sensitivity). The data were extracted at discrete strains at intervals of 0.05 , and second-order surface fits were used to find $\sigma=f(T, \dot{\varepsilon})$ at each strain, taking account of the scatter between repeat experiments. Smoothing of point-to-point fluctuations in the raw experimental data is best conducted as a simultaneous surface fit in both $T$ and $\dot{\varepsilon}$ because fitting at an isolated temperature or strain rate readily introduces nonphysical artifacts, such as crossover of curves at different $T$ or $\dot{\varepsilon}$. The goal was therefore to achieve a surface fit for flow stress $\sigma=f(T, \dot{\varepsilon})$, with smooth continuous gradients and curvature, while using the lowest order fit possible, to avoid any overfitting. Note that these arguments also apply to the generation of processing maps considered later in the paper.

\section{CORRECTION USING FE MODEL}

A $2 \times 2$ matrix of tests was chosen with conditions that fell inside the upper and lower limits of both temperature and strain rate: $700^{\circ} \mathrm{C}$ and $800^{\circ} \mathrm{C}, 10^{-2} \mathrm{~s}^{-1}$ and $10^{+0.5} \mathrm{~s}^{-1}$, subsequently expanded to a $3 \times 3$ matrix with an intermediate $T$ and $\dot{\varepsilon}$. The real tests experience $T$ and $\dot{\varepsilon}$ distributions above and below the nominal test value, so narrowing the test matrix for the FE analysis limited the uncertainty caused by extrapolation beyond the ranges of the input constitutive data.

Figure 6 shows FE results taken from the $2 \times 2$ matrix of conditions: the input and output stress-strain responses, indicating the stress offset $\Delta \sigma$, and the corrected constitutive data, with the predicted and experimental notional true stress-strain curve. The correction methodology works well, only requiring a single iteration to generate a corrected look-up table for $\sigma=f(T, \dot{\varepsilon}, \varepsilon)$. Note that the magnitude of the correction varies with strain, so that the interpretation of the extent of work softening may be significantly modified, as well as the magnitude of the flow stress. The analysis was then conducted over the $3 \times 3$ temperature and strain rate matrix, at every strain up to 0.6 in intervals of 0.05 . It is not claimed that this yields a definitive constitutive response because the correction applied depends on the temperature gradient and friction coefficient. But, the analysis demonstrates that there is a 
significant influence on the true stress-strain response of the inhomogeneity in the deformation. A more accurate correction could be made, given a better knowledge of the temperature distribution, via experiment and heat flow modeling.

The FE model in its current form can be used for further analyses-for example, to estimate the discrepancy between the nominal test conditions and those experienced in the central region of the sample. Figure 8 shows a number of predicted distributions in local conditions at the end of the deformation stage, for a high strain rate $\left(1 \mathrm{~s}^{-1}\right)$ at a test temperature $T=800^{\circ} \mathrm{C}$ at the center of the sample, with a temperature gradient of $100^{\circ} \mathrm{C}$. The plots of strain and strain rate show good qualitative equivalence with the experimentally observed deformation in figure $5 C$, with clear DMZs and deformation concentrated in the midplane of the sample. A semiquantitative comparison can be made with the extent of barreling, characterized by the ratio of the maximum cross-section area to that of the notional crosssection area in the absence of barreling-as in figure $3 B$ and $C$. Figure 9 shows a heat map fitted to the experimental data and to the corresponding predictions of the FE analysis. The trend of increased barreling from top left to bottom right is captured well, with reasonable quantitative agreement.

Figure 8 shows that the local strains and strain rates in the center of the sample are approximately four to five times higher than the nominal values. From equivalent

FIG. 8 Contour maps of the FE predictions at the end of a test at an initial central temperature of $800^{\circ} \mathrm{C}$ and nominal strain rate of $10^{+0} \mathrm{~S}^{-1}$, showing equivalent von Mises stress and strain, temperature, and axial strain rate.
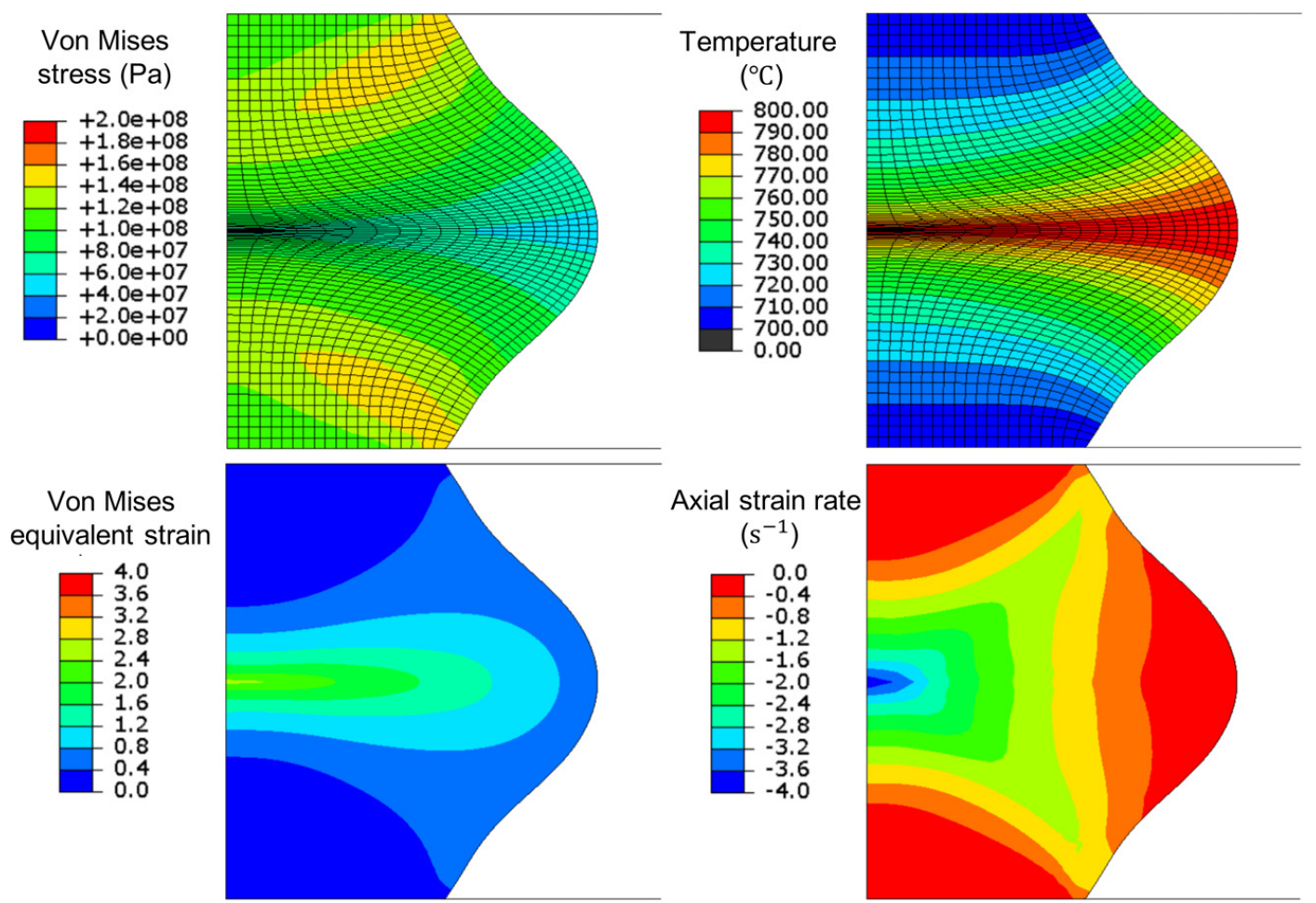

Axial strain rate
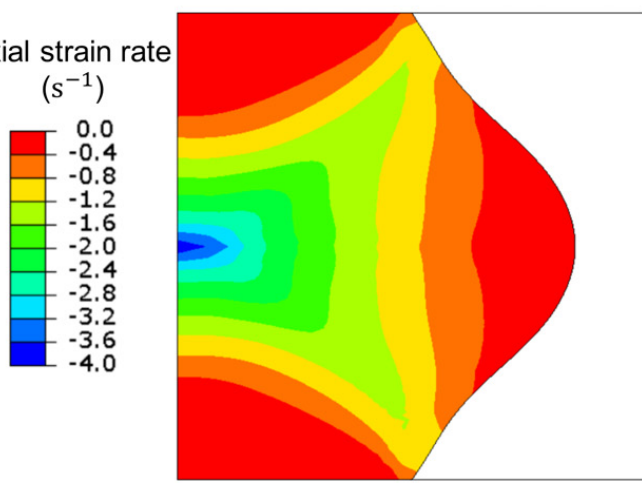
FIG. 9 Heat maps of the cross-sectional area showing $(A)$ experimentally measured barreling and $(B)$ barreling predicted by the FE model.
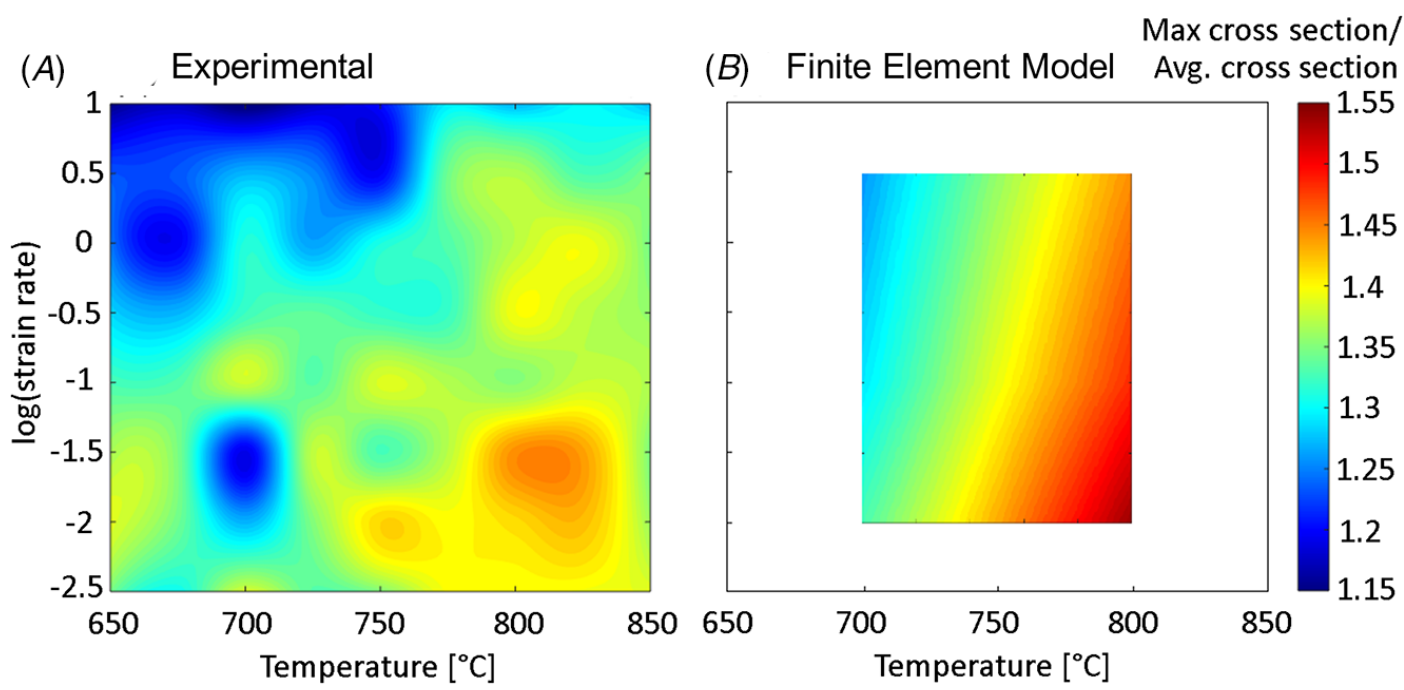

output at other strain rates, it is apparent that the kinematic self-similarity on the deformation means that this factor is almost independent of the imposed strain rate, in part because the imposed temperature profile is identical in all cases. The analysis demonstrates therefore that microstructural interpretation of dilatometer samples (or, equally, deeper analyses of the central region using crystal plasticity) must take due account of the inhomogeneity in the deformation conditions.

A further application of the FE corrected flow stress data is in the extraction of material characteristics from the constitutive data-such as strain-rate sensitivityas presented in the literature as processing maps. This is investigated in the next section, following a study of the influences of data sampling procedures on the form of these maps.

\section{Discussion}

\section{STRAIN-RATE SENSITIVITY PROCESSING MAPS}

The standard procedure for obtaining strain-rate sensitivity (processing) maps is as follows. $^{12}$

- Obtain flow stress values from experimental stress-strain curves at a predetermined strain value (usually 0.5 ).

- Fit cubic polynomials to $\log (\sigma)$ vs $\log (\dot{\varepsilon})$ values at each constant temperature.

- Differentiate the cubic polynomials to obtain the strain-rate sensitivity $m$.

- Plot $m$ on a map of $\log (\dot{\varepsilon})$ against temperature.

The results of this analysis are shown for the uncorrected data in figure 10A. The overall trend is an increase in strain-rate sensitivity with decreasing strain rate and increasing temperature. The analysis yields negative strain-rate sensitivity values for 
FIG. 10 The development of processing maps for $\mathrm{Zr}-2.5 \mathrm{Nb}$ using experimental stress data at $\varepsilon=0.5$. Showing $(A)$ the entire dataset, plotted as log of stress versus log of strain-rate data at each temperature, with the derivative of the cubic fit used to determine a contour map of strain-rate sensitivity, $m$. Reducing the data set in ( $B$ ) and $(C)$ sees different maxima and minima appear across the processing map, which differ in comparison with a previous study by Chakravartty et al. ${ }^{12}$ in (D) and demonstrate the dependence of the results on the number of data points included in the study. The true material stress calculated from the FE model produces a corrected map in ( $E$ ), which smooths out maxima and minima and shows only an increase in $m$ at higher temperatures and lower strain rates.

(A) Entire Dataset

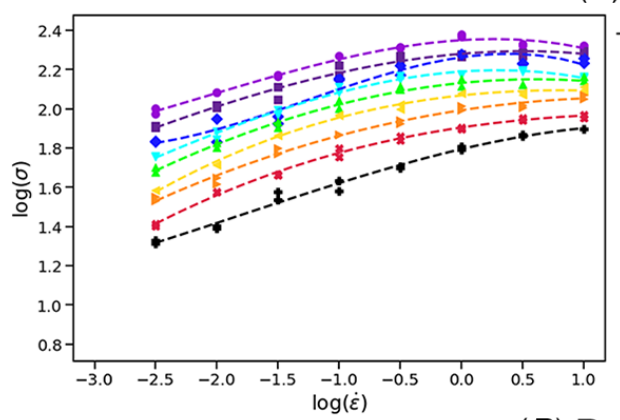

Temperature
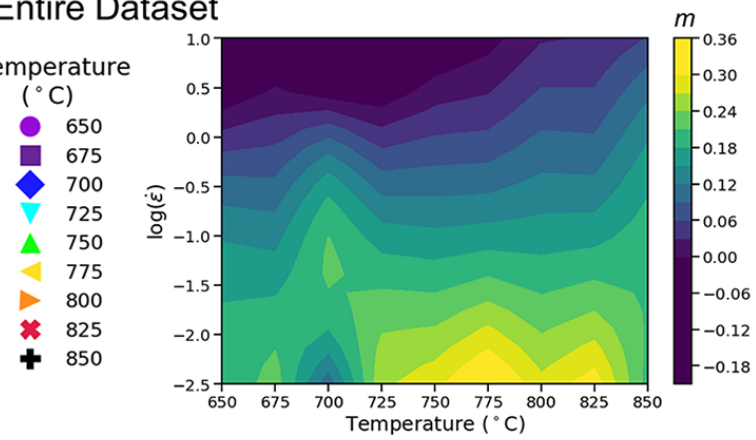

(B) Reduced Dataset (1)
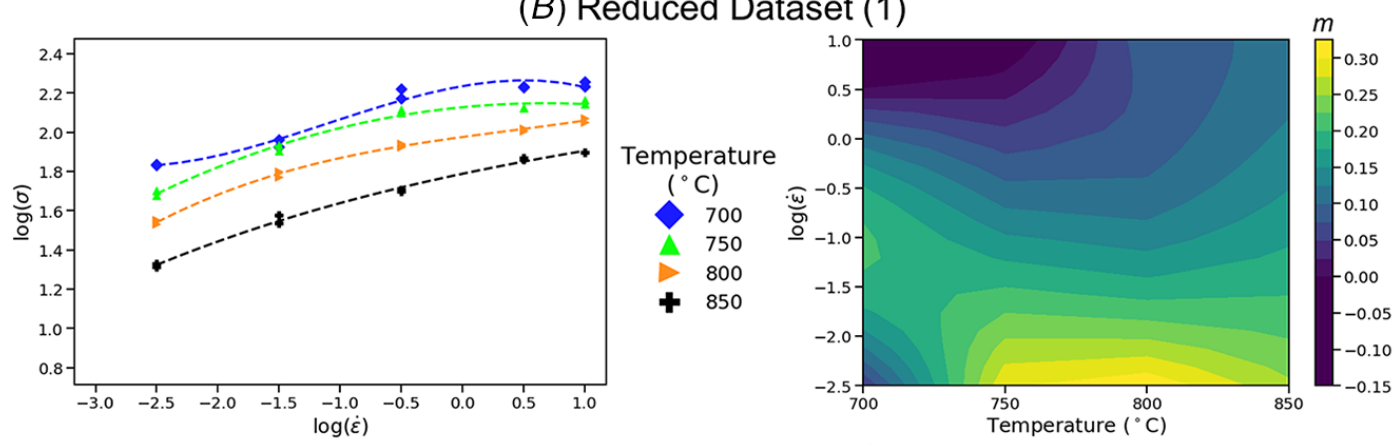

(C) Reduced Dataset (2)
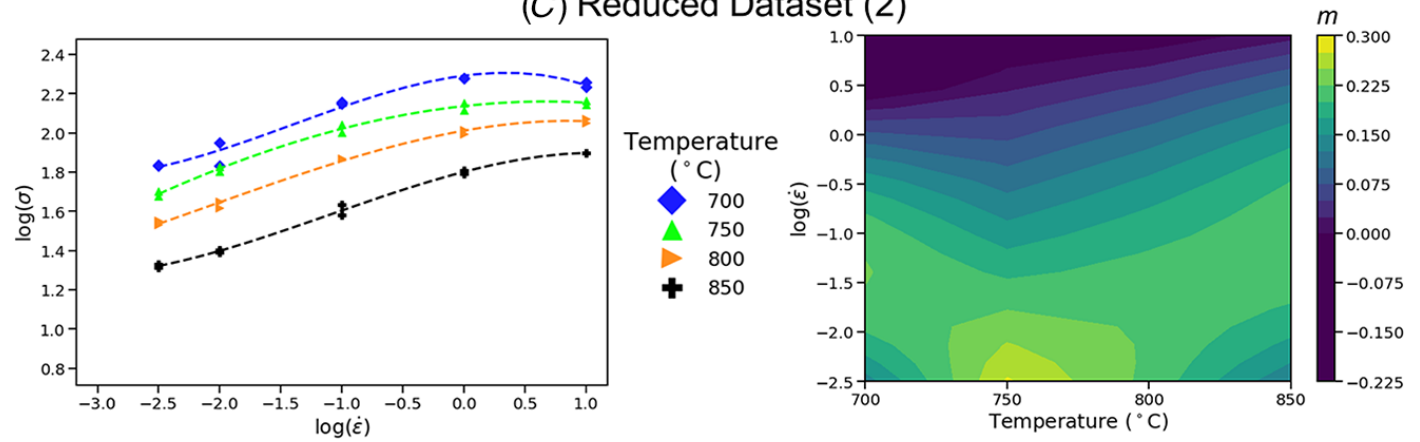

(D) Chakravartty et al. Dataset
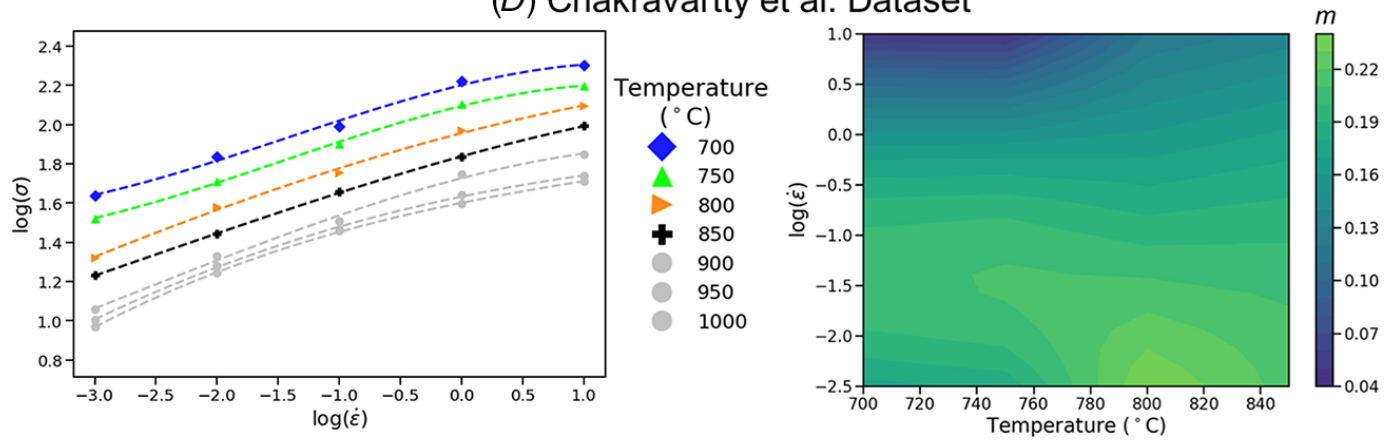
FIG. 10 (continued)

(E) FE Model Corrected Dataset
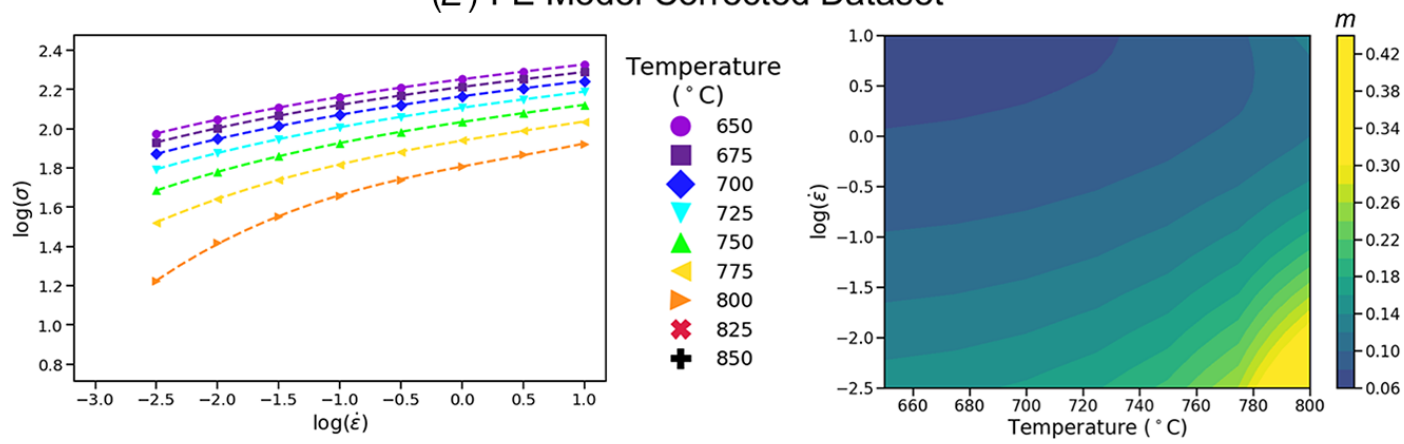

tests at low temperatures and high strain rates, which may be a consequence of adiabatic heating or nonuniform conditions in the sample (or both) or could be a numerical artifact due to the data sampling. In previous studies, adiabatic heating is corrected for using a variety of different methods. ${ }^{12,15,16,42,43}$ Here, the thermocouple on the sample measured a $50 \mathrm{~K}$ temperature spike during the initial stages of deformation at the highest strain rates, which is eliminated during the test by the temperature controller on the dilatometer. Nevertheless, the initial temperature spike may be sufficient to induce permanent softening in these samples, producing apparent negative strain-rate sensitivity.

The process map has a clear peak in strain-rate sensitivity at $775^{\circ} \mathrm{C}$, which would indicate optimum processing conditions. Peaks at $750^{\circ} \mathrm{C}$ to $775^{\circ} \mathrm{C}$ have been reported by other researchers. ${ }^{11,15,16}$ However, it is difficult to compare process maps directly because the maps are plotted differently, and the regimes change when they cover different process parameter ranges. ${ }^{12,18}$ They also invariably contain fewer measurement points (five temperatures and strain rates and sometimes fewer), with no repeated tests. To illustrate the variability in the map due to the size of the data set, subsets of the data produced here were used to produce process maps using only five different strain rates at each temperature. The resultant maps are shown in figure $10 B$ and $C$. These show that reducing the number of points noticeably changes the appearance of the processing map: it changes the values of the maximum and minimum strain rate measured and moves the position of the high strain-rate sensitivity peak by as much as $50^{\circ} \mathrm{C}$. This is a direct consequence of using a cubic polynomial with only five experimental points, of what is, unavoidably, somewhat noisy data. Interestingly, one of these new maps (fig. 10B) agrees reasonably well with the map from the data by Chakravartty et al., ${ }^{12}$ shown in figure 10D, unlike the original map with all the data points, which looked quite different.

To explore the effect of measurement uncertainty on individual measurements on the final process map, random noise normally distributed over a $\pm 5 \mathrm{MPa}$ range around the mean was added to the mean of the flow stresses measured at each 
FIG. 11 Analysis of the effect of $\pm 5 \mathrm{MPa}$ random noise on the predictions of the experimental processing map. Showing different $m$ maxima and minima appearing at different temperatures at a low strain rate $\left(10^{-2.5} \mathrm{~s}^{-1}\right)$.
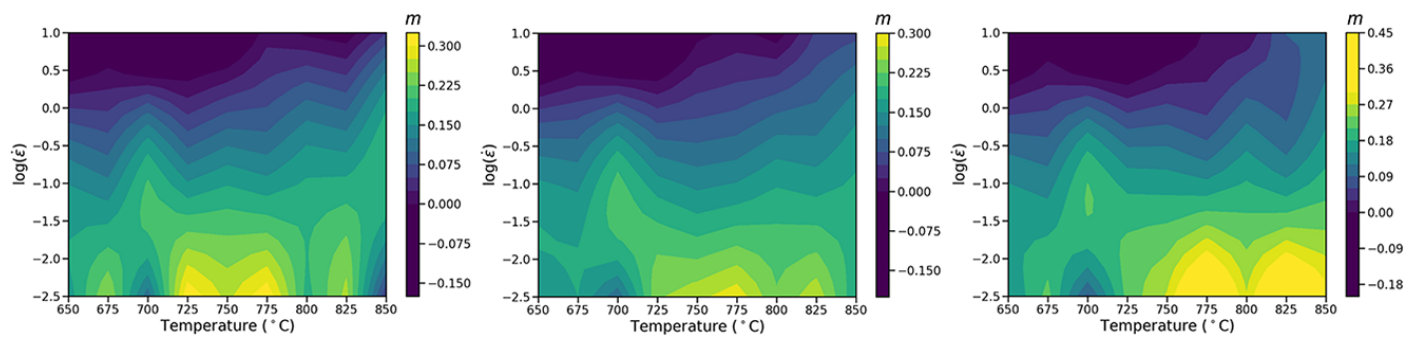

condition. The results of this exercise are shown in figure 11. Although all process maps show the same overall trend of increasing strain-rate sensitivity with decreasing strain rate, the temperature at which peaks in $m$ appear varies, as do the calculated values. This variation in map appearance is consistent with the variation seen in the literature, ${ }^{11,12,15,16,18}$ but it is again the consequence of using a cubic polynomial to fit the data. These maps use all the data points measured, and the differences among the maps are even more noticeable if fewer points are measured.

The data used to produce these processing maps assume ideal uniaxial compression conditions, which cannot be met during compression testing, especially at high temperatures where friction is always significant. New fast-testing solutions such as the Gleeble and the compression dilatometer used here introduce larger temperature gradients than in more conventional isothermal tests. In our case, and as demonstrated by the FE analysis, there are both clear friction and temperature effects that produce both a strain and strain-rate gradient along the gauge. The most obvious manifestation of these effects is sample barreling. In some processing map studies, a barreling correction is applied to the results to account for the sample shape change during deformation and the development of triaxiality. ${ }^{42,44,45}$ However, these corrections are insufficient since as the FE simulations show the link between the macroscopic nominal stress-strain curve and the actual stressstrain behavior of the material is not so simple. In each test, the macroscopic sample response is an average of the material behavior over all the different conditions in the sample. The range of conditions within a sample depends on the experimental setup and the constitutive behavior of the material. In materials with coarse microstructural features, the magnitude of these effects will vary from sample to sample. This is evident in the results for the tests at $700^{\circ} \mathrm{C}$ as can be seen in the heat map in figure 9, where the barreling varies significantly for samples tested at similar, relatively low strain rates. Because the processing map workflow involves fitting the data at different temperatures separately using a cubic polynomial, these effects propagate into the strain-rate sensitivity map, producing a peak in $m$. It is, therefore, not surprising that process maps have poor repeatability. 
In order to determine the true constitutive response of the material, data from the FE analysis were fitted using a surface fit in temperature strain-rate space, where it became clear that the scatter in the data did not justify the use of a polynomial of an order higher than two. Using this data to create a process map produces the map shown in figure $10 E$. The corrected data slightly decrease the gradient in strainrate sensitivity with temperature and completely remove the peaks in $m$ between $725^{\circ} \mathrm{C}$ and $800^{\circ} \mathrm{C}$, yielding a smooth increase in strain-rate sensitivity with increasing temperature and decreasing strain rate, peaking at $800^{\circ} \mathrm{C}$. The peak value of $\mathrm{m}$ at $800^{\circ} \mathrm{C}$ is somewhat higher than the measured values and could be a consequence of extrapolating beyond the calibration data at this extreme condition, where the strain and temperature gradients are highest and there is a lack of a correction at $850^{\circ} \mathrm{C}$.

The variation in deformation conditions experienced within one sample are reflected in variations in the microstructure seen after the test. These variations in microstructure provide a range of opportunities to find evidence for the regime predicted by the process maps, which helps explain why many studies are successful in validating the approach via postmortem microstructural analysis. ${ }^{7-26}$ Very few articles contain full sample metallographic images, such as those shown in figure 5, and only give limited consideration to the range of deformation conditions in the sample. However, strong emphasis is invariably given to examining the sample at the midsection, away from the platens, which implies that the microstructure does vary significantly in all cases.

Given this deformation inhomogeneity, identifying the best region to study becomes very difficult because there is no volume for which the conditions are constant. This is made even more difficult by the presence of coarse microstructural features such as grain boundary $\alpha$ that cause strain localization and introduce asymmetry to the deformation. Nevertheless, with the assistance of the FE simulations, we can estimate the actual process conditions in the center of the samples tested here. The predicted effective strain and strain rates at the midpoint of four of the samples are shown in table 1. The predicted strain and strain-rate values are some two to five times higher than the nominal test strain value. This implies that even if one is careful to analyze only the midsection of the sample, the

TABLE 1 Comparison between nominal strain (0.69) and strain rate and the finite element (FE) predicted strain and strain rate, at the center of the sample at $700^{\circ} \mathrm{C}$ and $800^{\circ} \mathrm{C}$

\begin{tabular}{l|c|c|c} 
Temperature $\left({ }^{\circ} \mathrm{C}\right)$ & Nominal Strain Rate $\left(\mathrm{s}^{-1}\right)$ & FE Predicted Strain Rate $\left(\mathrm{s}^{-1}\right)$ & FE Predicted Strain \\
\hline 700 & $10^{+0}$ & $10^{+0.5}$ & $1.6-2.0$ \\
700 & $10^{-2.5}$ & $10^{-1.9}$ & $2.8-3.2$ \\
800 & $10^{+0}$ & $10^{+0.6}$ & $2.8-3.2$ \\
800 & $10^{-2.5}$ & $10^{-1.9}$ & $3.6-4.0$ \\
\hline
\end{tabular}


microstructure observed will usually not correspond to the nominal test conditions identified in the process map. The difference in total deformation is most significant: whereas the assumed, nominal strain is 0.7 , the actual strain can be as high as 4. Furthermore, the difference in the strain and strain rates increases with increasing temperature and decreasing strain rate, a consequence of the increasing strain-rate sensitivity and its effect on increasing the deformation inhomogeneity observed in Figure 5.

These considerations make it difficult to analyze the microstructural changes in the samples tested, as shown in figure 12. For example, it could be argued that, at $800^{\circ} \mathrm{C}$, there is a trend toward more globularization of the microstructure at the lower strain rates and at the same temperature, but because the total strain at the lower strain rate is twice that at the higher strain rate, it is difficult to say that this is purely a strain-rate effect. In this case, strain rate is probably the main effect because the microstructure changes only very slowly at large strains. There is a general trend toward more globularization or recrystallization in the processing map conditions where the strain-rate sensitivity is higher, ${ }^{20}$ but it is not possible to be more quantitative.

Texture control is an important aim of the thermomechanical processing of $\mathrm{Zr}-2.5 \mathrm{Nb}$ because it strongly affects in-reactor performance. The pole figures for the material at the midpoint of the samples are shown in figure 13 for three different temperatures and two extreme nominal strain rates. There appears to be clear trends in the texture development, both with temperature and strain rate: the texture appears to be stronger at the higher strain rates and the 0002 poles seem to gradually align toward the radial directions as temperature increases and strain rate decreases. However, because the texture of this material is strongly affected by the amount of deformation, ${ }^{39}$ it cannot be determined whether these changes are driven by time-dependent strain-rate changes or if they are simply a consequence of the higher level of strain reached at the lower strain rates.

The EBSD analysis confirms the observations from the metallographic examination. Figure $13 \mathrm{H}$ and $I$ shows two maps of the microstructure after deformation at $800^{\circ} \mathrm{C}$. There is clearly more evidence for recrystallization/globularization in the material deformed at the lower strain rate, although it is noticeable that the recrystallized grains appear in clusters of similar orientation-the majority with 0002 basal poles aligned in the radial directions (perpendicular to the compression direction). Surprisingly, the $\beta$ texture appears to be much stronger after deformation at the higher strain rate. The $\beta$ texture develops a cube component, with $100 \| C D$, which is unusual in lacking the axial symmetry expected for uniaxial compression, which could be due to the inhomogeneity in deformation in the sample and the interaction of large prior $\beta$ grains. ${ }^{3}$ In $\mathrm{Zr}-2.5 \mathrm{Nb}$ deformed at $800^{\circ} \mathrm{C}$, the texture is created during both deformation and phase transformation on cooling; therefore, it cannot be completely determined by the deformation conditions.

Given the inhomogeneity of the dual-phase microstructures and textures, it is not surprising that there is little agreement in the ideal processing conditions for 
FIG. 12 Optical polarized light micrographs at the center of deformed Zr-2.5Nb compression samples. Showing differences in the $\alpha$-grain structures at room temperature, following deformation at different temperatures and nominal strain rates of $(A) 700^{\circ} \mathrm{C}, 10^{+0} \mathrm{~S}^{-1}$; (B) $700^{\circ} \mathrm{C}, 10^{-2.5} \mathrm{~S}^{-1}$; (C) $800^{\circ} \mathrm{C}, 10^{+0} \mathrm{~S}^{-1}$; (D) $800^{\circ} \mathrm{C}, 10^{-2.5} \mathrm{~s}^{-1}$; (E) $850^{\circ} \mathrm{C}, 10^{+0} \mathrm{~s}^{-1}$; and $(F) 850^{\circ} \mathrm{C}, 10^{-2.5} \mathrm{~s}^{-1}$.

(A) $700^{\circ} \mathrm{C}, 10^{+0} \mathrm{~s}^{-1}$

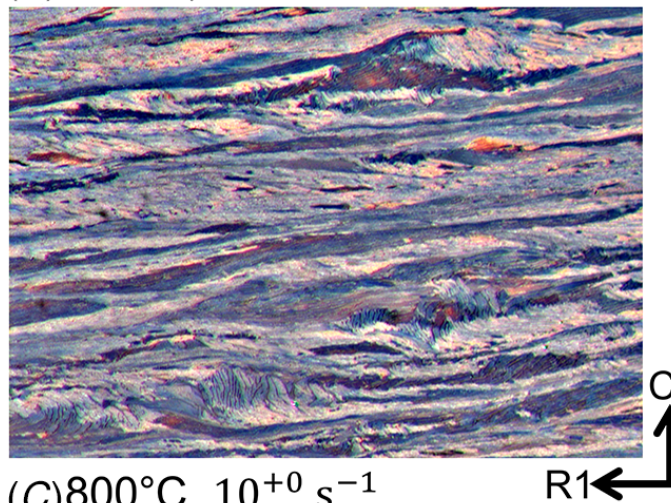

(C) $800^{\circ} \mathrm{C}, 10^{+0} \mathrm{~s}^{-1}$

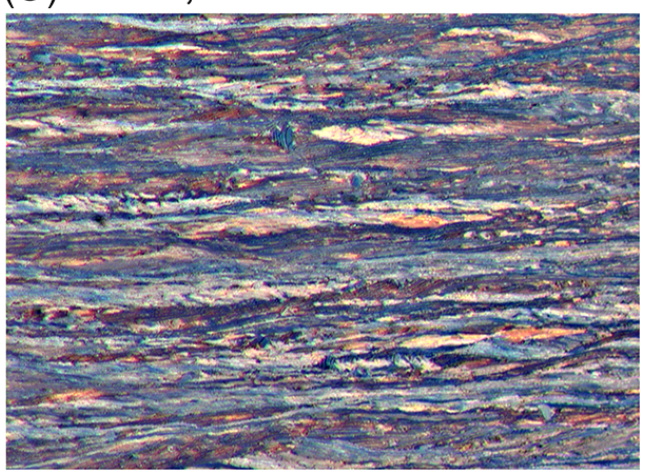

$(E) 850^{\circ} \mathrm{C}, 10^{+0} \mathrm{~s}^{-1}$

$\mathrm{R} 1 \longleftarrow$

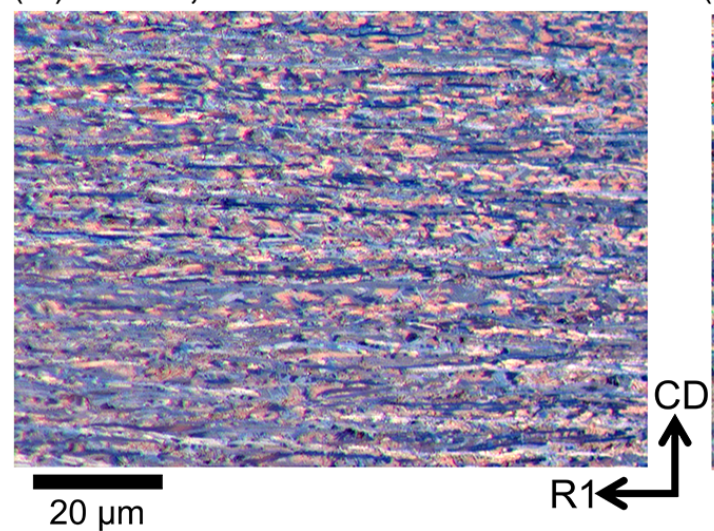

(B) $700^{\circ} \mathrm{C}, 10^{-2.5} \mathrm{~s}^{-1}$
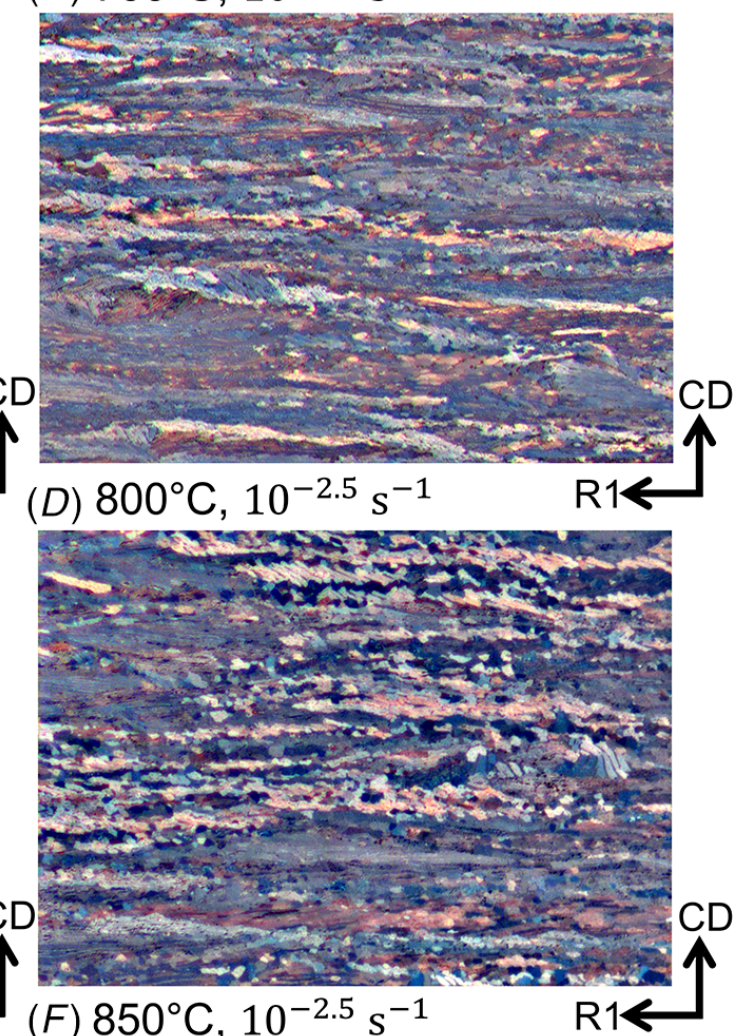

(F) $850^{\circ} \mathrm{C}, 10^{-2.5} \mathrm{~s}^{-1}$

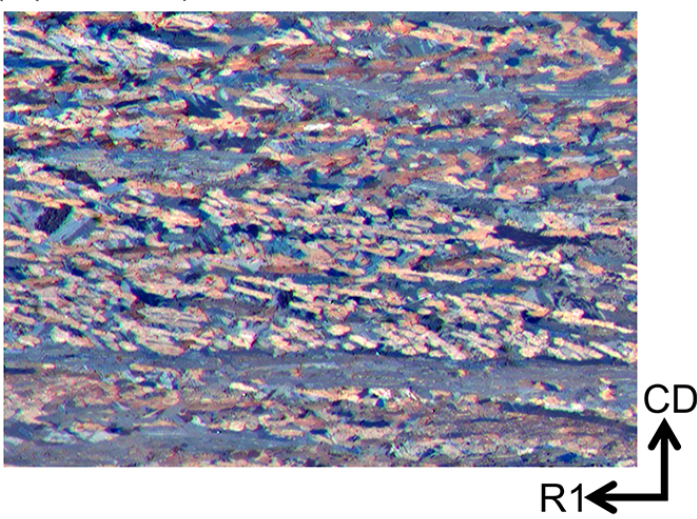

$\mathrm{Zr}-2.5 \mathrm{Nb}$ recommended in the literature. ${ }^{11,12,15,16}$ The inhomogeneity of the deformation behavior exacerbates two consequences within the processing map methodology. First, the measurement reproducibility is affected, meaning the same ideal process conditions will rarely be predicted. Second, if a regime is identified for investigation, the deformation state of the material analyzed, using optical microscopy or EBSD, is unlikely to correspond with the processing parameters 
FIG. 13 The $\alpha$-phase pole figures taken from the central deformed region of the $\mathrm{Zr}-2.5 \mathrm{Nb}$ compression samples. Showing the texture changes from $(A)$ the starting material and after deformation at $(B) 700^{\circ} \mathrm{C}, 10^{+0} \mathrm{~S}^{-1} ;(C) 700^{\circ} \mathrm{C}$, $10^{-2.5} \mathrm{~S}^{-1}$; (D) $800^{\circ} \mathrm{C}, 10^{+0} \mathrm{~S}^{-1}$; (E) $800^{\circ} \mathrm{C}, 10^{-2.5} \mathrm{~s}^{-1}$; ( F ) $850^{\circ} \mathrm{C}, 10^{+0} \mathrm{~S}^{-1}$; and (G) $850^{\circ} \mathrm{C}, 10^{-2.5} \mathrm{~s}^{-1}$. Fine $\alpha$-phase orientation maps, at the center of $\mathrm{Zr}-2.5 \mathrm{Nb}$ samples deformed at $800^{\circ} \mathrm{C}$, show microstructures following deformation at applied nominal strain rates of $(H) 10^{+0} \mathrm{~S}^{-1}$ and $(I) 10^{-2.5} \mathrm{~s}^{-1}$. Much larger $\alpha$-grains, with the 0002 basal pole oriented in the radial plane, appear following low strain-rate deformation.

(A)

Start

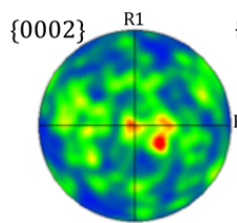

$(B)$ $700^{\circ} \mathrm{C}$ $10^{+0} \mathrm{~s}^{-1}$
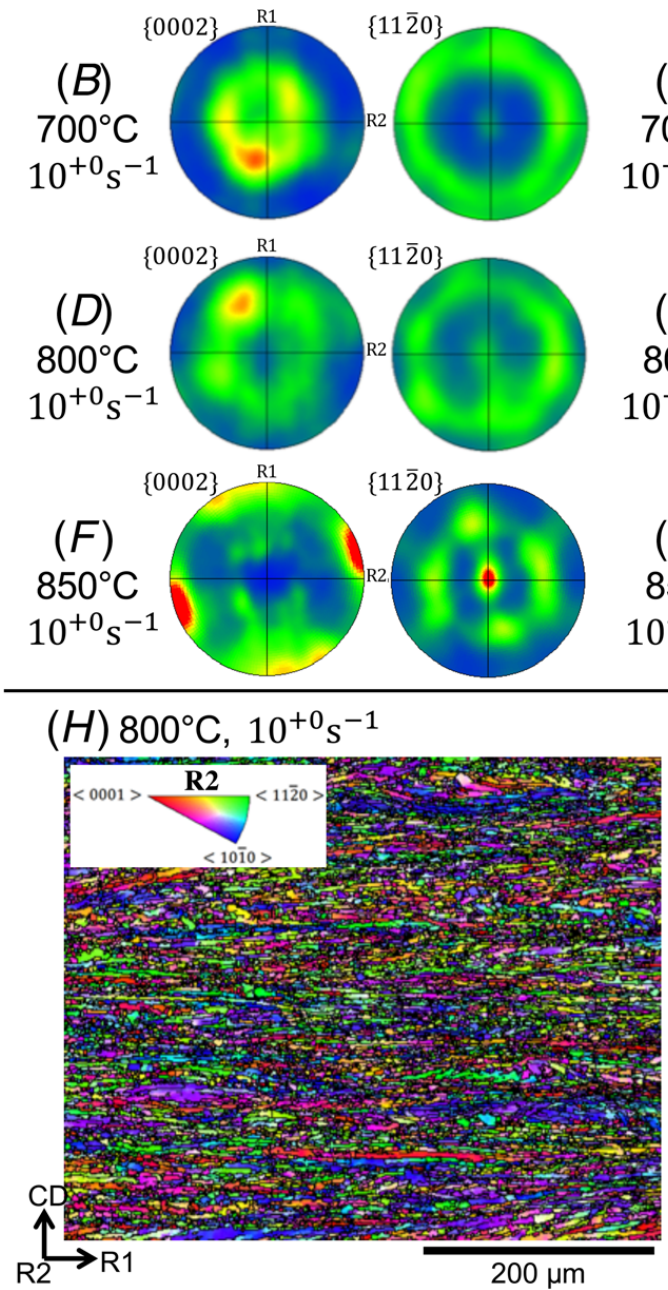
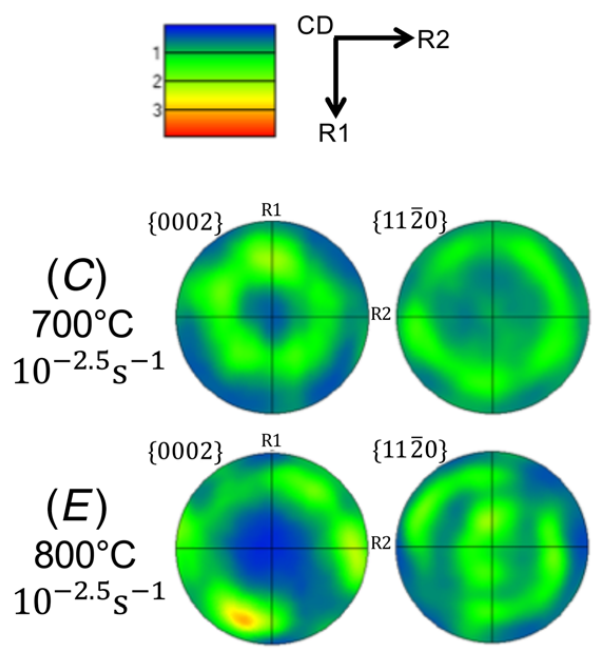

(G) $850^{\circ} \mathrm{C}$ $10^{-2.5} \mathrm{~s}^{-1}$
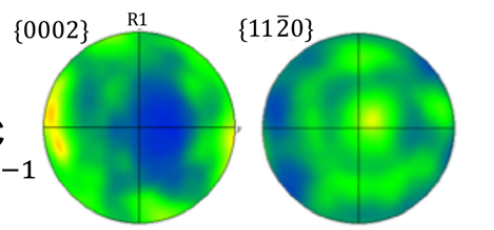

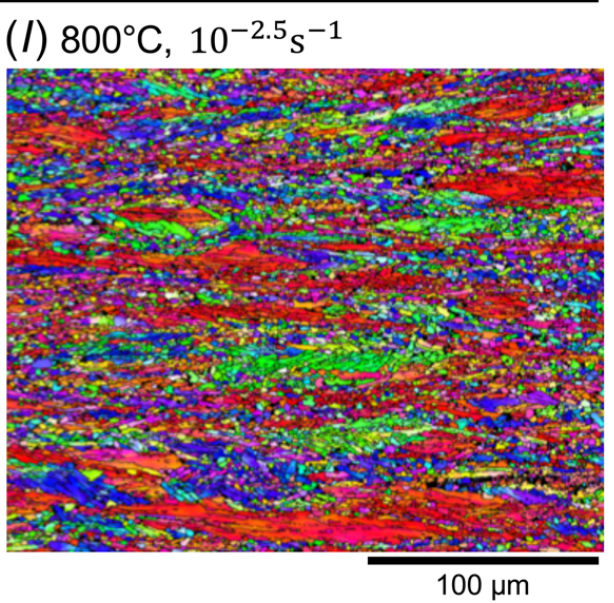

recommended in the map, particularly if the ex situ observations are made at the center of the specimen. As these results show, optimal processing regimes can only be discovered using small-scale, hot-compression testing if careful consideration is given to the experimental setup to determine the true deformation conditions. 


\section{Conclusions}

Despite the convenience and popularity of the processing map approach, there are inherent issues with the methodology. The use of high-temperature uniaxial compressive tests leads to deformation inhomogeneity in the sample during the test, which affects the measured stress-strain response and creates microstructural inhomogeneity in the sample. Because the deformation inhomogeneity depends on the experimental conditions such as the thermal gradient in the sample and the friction at the platens, the measured stress-strain curves are inherently difficult to reproduce. Because the calculation of strain-rate sensitivity relies on fitting data from different temperatures separately, using a cubic polynomial, it is very sensitive to noise in the data. The procedure overfits the data, which is particularly problematic when the samples are tested at only four or five different strain rates and without repeat. For $\mathrm{Zr}-2.5 \mathrm{Nb}$ deformed in the $\alpha+\beta$ region, there seems to be only a gradual increase in strain-rate sensitivity with increasing temperature and decreasing strain rate. Because of the deformation gradients in the sample, it is difficult to link microstructure evolution to processing conditions without a rigorous FE analysis of the tests. Thus, although the processing map methodology appears to be a fast method of identifying optimum processing conditions, it requires a highly detailed analysis of the test to improve reproducibility and to make the best of a large data set of thermomechanical testing regimes.

\section{ACKNOWLEDGMENTS}

This research was sponsored by Rolls-Royce plc. and was funded by LightForm, a UK Engineering and Physical Sciences Research Council program grant (EP/R001715/1).

\section{References}

1. K. L. Murty, "Applications of Crystallographic Textures of Zirconium Alloys in the Nuclear Industry," in Zirconium in the Nuclear Industry: Eighth International Symposium, ed. C. M. Eucken and L. F. P. Van Swam (West Conshohocken, PA: ASTM International, 1989), 570-595, https://doi.org/10.1520/STP18888S

2. S. Banerjee, "Nuclear Applications: Zirconium Alloys," in Encyclopedia of Materials: Science and Technology, 2nd ed., ed. K. H. Cahn, R. W. Flemings, B. Ilschner, E. J. Kramer, S. Mahajan, and P. Veyssière (Amsterdam: Elsevier Science, 2001), 6287-6299, https:// doi.org/10.1016/B0-08-043152-6/01117-7

3. C. S. Daniel, P. D. Honniball, L. Bradley, M. Preuss, and J. Quinta da Fonseca, "Texture Development during Rolling of $\alpha+\beta$ Dual-Phase ZrNb Alloys," in Zirconium in the Nuclear Industry: Eighteenth International Symposium, ed. R. J. Comstock and A. T. Motta (West Conshohocken, PA: ASTM International, 2017), 151-179, https://doi.org /10.1520/STP159720160070

4. Y. V. R. K. Prasad, H. L. Gegel, S. M. Doraivelu, J. C. Malas, J. T. Morgan, K. A. Lark, and D. R. Barker, "Modeling of Dynamic Material Behavior in Hot Deformation: Forging of Ti-6242," Metallurgical Transactions A 15 (1984): 1883-1892, https://doi.org/10.1007 /BF02664902 
5. Y. V. R. K. Prasad and S. Sasidhara, Hot Working Guide: A Compendium of Processing Maps, 1st ed. (Cleveland, OH: ASM International, 1997).

6. S. Ghosh, "Interpretation of Microstructural Evolution Using Dynamic Materials Modeling," Metallurgical and Materials Transactions A 31 (2000): 2973-2974.

7. J. K. Chakravartty, Y. V. R. K. Prasad, and M. K. Asundi, "Processing Map for Hot Working of Alpha-Zirconium," Metallurgical Transactions A 22 (1991): 829-836, https://doi.org /10.1007/BF02658992

8. J. K. Chakravartty, Y. V. R. K. Prasad, and M. K. Asundi, "Processing Map and Hot Working Characteristics of Zircaloy-2," in Zirconium in the Nuclear Industry: Ninth International Symposium, ed. C. M. Eucken and A. M. Garde (West Conshohocken, PA: ASTM International, 1991), 48-61, https://doi.org/10.1520/STP25498S

9. A. Sarkar and J. K. Chakravartty, "Hot Deformation Behavior of Zr-1Nb Slloy: Characterization by Processing Map," Journal of Nuclear Materials 440 (2013): 136-142, https:// doi.org/10.1016/j.jnucmat.2013.04.080

10. Y. B. Tan, L. H. Yang, C. Tian, R. P. Liu, X. Y. Zhang, and W. C. Liu, "Hot Deformation Behavior of ZrTiAIV Alloy with a Coarse Grain Structure in the $\beta$ Phase Field," Materials Science and Engineering A 577 (2013): 218-224, https://doi.org/10.1016/j.msea.2013.04.056

11. K. K. Saxena, S. D. Yadav, S. Sonkar, V. Pancholi, G. P. Chaudhari, D. Srivastava, G. K. Dey, S. K. Jha, and N. Saibaba, "Effect of Temperature and Strain Rate on Deformation Behavior of Zirconium Alloy: Zr-2.5Nb," Procedia Materials Science 6 (2014): 278-283, https:// doi.org/10.1016/j.mspro.2014.07.035

12. J. K. Chakravartty, R. Kapoor, A. Sarkar, V. Kumar, S. K. Jha, N. Saibaba, and S. Banerjee, "Identification of Safe Hot-Working Conditions in Cast Zr-2.5Nb, in Zirconium in the Nuclear Industry: 17th Volume, ed. B. Comstock and P. Barberis (West Conshohocken, PA: ASTM International, 2015), 259-281, https://doi.org/10.1520/STP154320120197

13. J. K. Chakravartty, S. Banerjee, Y. V. R. K. Prasad, and M. K. Asundi, "Hot-Working Characteristics of Zircaloy-2 in the Temperature Range of $650-950^{\circ} \mathrm{C}$," Journal of Nuclear Materials 187 (1992): 260-271, https://doi.org/10.1016/0022-3115(92)90506-G

14. J. K. Chakravartty, S. Banerjee, and Y. V. R. K. Prasad, "Superplasticity in $\beta$-Zirconium: A Study Using a Processing Map," Scripta Metallurgica et Materialia 26 (1992): 75-78, https://doi.org/10.1016/0956-716X(92)90372-L

15. J. K. Chakravartty, G. K. Dey, S. Banerjee, and Y. V. R. K. Prasad, "Characterization of Hot Deformation Behavior of Zr-2.5Nb-0.5Cu Using Processing Maps," Journal of Nuclear Materials 218 (1995): 247-255, https://doi.org/10.1016/0022-3115(94)00379-3

16. J. K. Chakravartty, G. K. Dey, S. Banerjee, and Y. V. R. K. Prasad, "Dynamic Recrystallisation during Hot Working of Zr-2.5Nb: Characterisation Using Processing Maps," Materials Science and Technology 12 (1996): 705-716, https://doi.org/10.1179 /026708396790122431

17. R. Kapoor and J. K. Chakravartty, "Characterization of Hot Deformation Behavior of Zr-2.5Nb in $\beta$ Phase," Journal of Nuclear Materials 306 (2002): 126-133, https://doi.org /10.1016/S0022-3115(02)01290-4

18. R. Kapoor, J. K. Chakravartty, C. C. Gupta, and S. L. Wadekar, "Characterization of Superplastic Behaviour in the $(\alpha+\beta)$ Phase Field of Zr-2.5wt.\%Nb Alloy," Materials Science and Engineering A 392 (2005): 191-202, https://doi.org/10.1016/j.msea.2004.09.023

19. J. K. Chakravartty, R. Kapoor, S. Banerjee, and Y. V. R. K. Prasad, "Characterization of Hot Deformation Behavior of Zr-1Nb-1Sn Alloy," Journal of Nuclear Materials 362 (2007): 75-86, https://doi.org/10.1016/j.jnucmat.2006.11.007

20. J. K. Chakravartty, R. Kapoor, A. Sarkar, and S. Banerjee, "Dynamic Recrystallization in Zirconium Alloys," Journal of ASTM International 7 (2010): 1-17, https://doi.org /10.1520/JAI103003 
21. Y. V. R. K. Prasad, T. Seshacharyulu, S. C. Medeiros, and W. G. Frazier, "Effect of Prior $\beta$-Grain Size on the Hot Deformation Behavior of Ti-6Al-4V: Coarse vs Coarser," Journal of Materials Engineering and Performance 9 (2000): 153-160, https://doi.org/10.1361 $/ 105994900770346097$

22. T. Seshacharyulu, S. C. Medeiros, W. G. Frazier, and Y. V. R. K. Prasad, "Hot Working of Commercial Ti-6Al-4V with an Equiaxed $\alpha-\beta$ Microstructure: Materials Modeling Considerations," Materials Science and Engineering A 284 (2000): 184-194, https://doi.org /10.1016/S0921-5093(00)00741-3

23. V. V. Balasubrahmanyam and Y. V. R. K. Prasad, "Hot Deformation Mechanisms in Ti-5.5Al-1Fe Alloy," Journal of Materials Engineering and Performance 10 (2001): 731-739, https://doi.org/10.1361/105994901770344629

24. T. Seshacharyulu, S. C. Medeiros, W. G. Frazier, and Y. V. R. K. Prasad, "Microstructural Mechanisms during Hot Working of Commercial Grade Ti-6Al-4V with Lamellar Starting Structure," Materials Science and Engineering A 325 (2002): 112-125, https://doi.org /10.1016/S0921-5093(01)01448-4

25. L. J. Huang, L. Geng, A. B. Li, X. P. Cui, H. Z. Li, and G. S. Wang, "Characteristics of Hot Compression Behavior of Ti-6.5Al-3.5Mo-1.5Zr-0.3Si Alloy with an Equiaxed Microstructure," Materials Science and Engineering A 505 (2009): 136-143, https://doi.org /10.1016/j.msea.2008.12.041

26. I. Sen, R. S. Kottada, and U. Ramamurty, "High Temperature Deformation Processing Maps for Boron Modified Ti-6Al-4V Alloys," Materials Science and Engineering A 527 (2010): 6157-6165, https://doi.org/10.1016/j.msea.2010.06.044

27. S. Ghosh, "Interpretation of Flow Instability Using Dynamic Material Modeling," Metallurgical and Materials Transactions A 33 (2002): 1569-1572, https://doi.org/10.1007/s11661002-0081-x

28. F. Montheillet, J. J. Jonas, and K. W. Neale, "Modeling of Dynamic Material Behavior: A Critical Evaluation of the Dissipator Power Co-Content Approach," Metallurgical and Materials Transactions A 27 (1996): 232-235, https://doi.org/10.1007/BF02647764

29. I. Weiss, F. H. Froes, D. Eylon, and G. E. Welsch, "Modification of Alpha Morphology in Ti-6Al-4V by Thermomechanical Processing," Metallurgical Transactions A 17 (1986): 1935-1947, https://doi.org/10.1007/BF02644991

30. S. L. Semiatin, V. Seetharaman, and I. Weiss, "Flow Behavior and Globularization Kinetics during Hot Working of Ti-6Al-4V with a Colony Alpha Microstructure," Materials Science and Engineering A 263 (1999): 257-271, https://doi.org/10.1016/S0921-5093(98)01156-3

31. E. B. Shell and S. L. Semiatin, "Effect of Initial Microstructure on Plastic Flow and Dynamic Globularization during Hot Working of Ti-6Al-4V," Metallurgical and Materials Transactions A 30 (1999): 3219-3229, https://doi.org/10.1007/s11661-999-0232-4

32. S. Mironov, M. Murzinova, S. Zherebtsov, G. A. Salishchev, and S. L. Semiatin, "Microstructure Evolution during Warm Working of Ti-6Al-4V with a Colony- $\alpha$ Microstructure," Acta Materialia 57 (2009): 2470-2481, https://doi.org/10.1016/j.actamat.2009.02.016

33. S. Zherebtsov, M. Murzinova, G. Salishchev, and S. L. Semiatin, "Spheroidization of the Lamellar Microstructure in Ti-6Al-4V Alloy during Warm Deformation and Annealing," Acta Materialia 59 (2011): 4138-4150, https://doi.org/10.1016/j.actamat.2011.03.037

34. S. Banerjee, "Displacive and Diffusional Transformations of the Beta Phase in Zirconium Alloys," in Zirconium in the Nuclear Industry: 17th Volume, ed. B. Comstock and P. Barberis (West Conshohocken, PA: ASTM International, 2015), 23-51, https://doi.org /10.1520/STP154320130039

35. P. S. Davies, "An Investigation of Microstructure and Texture Evolution in the Near- $\alpha$ Titanium Alloy Timetal 834" (PhD thesis, University of Sheffield, 2009).

36. P. S. Davies, B. P. Wynne, W. M. Rainforth, M. J. Thomas, and P. L. Threadgill, "Development of Microstructure and Crystallographic Texture during Stationary 
Shoulder Friction Stir Welding of Ti-6Al-4V," Metallurgical and Materials Transactions A 42 (2011): 2278-2289, https://doi.org/10.1007/s11661-011-0606-2

37. M. Humbert, F. Wagner, H. Moustahfid, and C. Esling, "Determination of the Orientation of a Parent $\beta$ Grain from the Orientations of the Inherited $\alpha$ Plates in the Phase Transformation from Body-Centred Cubic to Hexagonal Close Packed," Journal of Applied Crystallography 28 (1995): 571-576, https://doi.org/10.1107/S0021889895004067

38. M. Humbert and N. Gey, "The Calculation of a Parent Grain Orientation from Inherited Variants for Approximate (B.C.C.-H.C.P.) Orientation Relations," Journal of Applied Crystallography 35 (2002): 401-405, https://doi.org/10.1107/S0021889802005824

39. C. S. Daniel, P. D. Honniball, L. Bradley, M. Preuss, and J. Quinta da Fonseca, "A Detailed Study of Texture Changes during Alpha-Beta Processing of a Zirconium Alloy," Journal of Alloys and Compounds 804 (2019): 65-83, https://doi.org/10.1016/j.jallcom.2019.06.338

40. C. S. Daniel, C. J. Peyton, and J. Quinta da Fonseca, "High Temperature Compression Studies of a Zr-2.5Nb Alloy Using Deformation Dilatometer [Data set]," Zenodo (2019), https://doi.org/10.5281/zenodo.3374512

41. P. Jedrasiak and H. R. Shercliff, Finite Element Modelling of Small-Scale Hot Deformation Testing, Cambridge University Engineering Department Technical Report CUED/C-MATS/ TR.264 (Cambridge, UK: Cambridge University, 2020).

42. M. Hu, L. Dong, Z. Zhang, X. Lei, R. Yang, and Y. Sha, "Correction of Flow Curves and Constitutive Modelling of a Ti-6Al-4V Alloy," Metals 8, no. 4 (2018): 256, https://doi.org $/ 10.3390 /$ met8040256

43. J. Zhang and H. Di, "Deformation Heating and Flow Localization in Ti-15-3 Metastable $\beta$ Titanium Alloy Subjected to High Z Deformation," Materials Science and Engineering A 676 (2016): 506-509, https://doi.org/10.1016/j.msea.2016.09.011

44. P. Honarmandi and M. Aghaie-Khafri, "Hot Deformation Behavior of Ti-6Al-4V Alloy in $\beta$ Phase Field and Low Strain Rate," Metallography, Microstructure and Analysis 2 (2013): 13-20, https://doi.org/10.1007/s13632-012-0052-6

45. P. Wanjara, M. Jahazi, H. Monajati, S. Yue, and J.-P. Immarigeon, "Hot Working Behavior of Near- $\alpha$ Alloy IMI834," Materials Science and Engineering A 396 (2005): 50-60, https://doi.org/10.1016/j.msea.2004.12.005

\section{Discussion}

Questions from Alexis Gaillac, Framatome:

1. Does the friction have more or less impact compared to temperature inhomogeneity during your compression test?

2. Why are you using this dilatometer compression test instead of a standard compression test in a furnace or even torsion tests, which are without friction and with less temperature inhomogeneity?

3. The order of magnitude of strain is 1 to 10 and strain rate is $1^{-1}$ to $10^{-1}$ during industrial hot forming processes (forging, extrusion, rolling). Your processing maps seem far from these processing conditions. How do you handle these differences for an industrial application?

\section{Authors' Response:}

1. Temperature inhomogeneity has the most impact on the barreling.

2. Sample changeover is very quick using the dilatometer, meaning it is possible to test a large matrix of test conditions and investigate the effect of 
incremental changes in temperature and strain rate. Our work demonstrates the importance of acquiring a large number of data points to constrain any fit to the log of stress versus log of strain-rate plots when deriving processing maps of strain-rate sensitivity. Compression tests using a furnace could reduce temperature inhomogeneity and barreling (although platens can still act as heat sinks, reducing temperature at the contact points), but such tests require much longer sample changeover times for heating/cooling samples and for adjusting furnace temperature, making it very difficult to investigate a similar-sized test matrix. Our additional experiments, using Gleeble and Servotest thermomechanical testers, not presented here, show barreling will always result to some extent in dual-phase $\mathrm{Zr}$ and $\mathrm{Ti}$ alloys, affecting the measured stress response.

3. Strain rates during forging are often similar to those used in these tests. We also wanted to use strain rates comparable to those published in other articles with processing maps for these alloys. However, the FE model showed that microstructures at the center of compression samples are much higher than the macrostrain imposed. Although the ideal true strain only reached 0.7 , the predicted strain in the FE model could be as high as 4.0. Strain rates were also up to five times higher than the nominal applied rate.

The test conditions covered by the processing map are slightly below the industrial strain rates for extrusion, for example. Our study shows only a gradual increase in strain-rate sensitivity at lower strain rates and higher temperatures, a general trend that could be applied to optimize industrial processing routes. Nevertheless, it is important to note that we do not recommend any specific combination of optimized processing conditions here (temperature and strain rate). Previous studies on $\mathrm{Zr}-2.5 \mathrm{Nb}$ processing maps imply that the material should be processed in "idealized" regimes where peaks appear in the strain-rate sensitivity map, which we comprehensively show arise from experimental noise and scatter in the data.

Question from Kit Coleman, ANT International:-How many times was the starting ingot melted in vacuum? This can make a difference in the residual halogens that, in turn, may affect fracture toughness and high temperature oxidation of Zr-2.5Nb.

Authors' Response:-The starting ingot was triple melted in vacuum to reduce the risk of nitrides and improve homogeneity. The oxygen content of the starting material was measured as $0.10 \mathrm{wt} . \%$ throughout the block, which is in the typical range of 0.09 to $0.15 \mathrm{wt} . \%$ for $\mathrm{Zr}-2.5 \mathrm{Nb}$ alloys. The hydrogen content was within the specified maximum of $25 \mathrm{ppm}$ and measured to be $<12 \mathrm{ppm}$ throughout the starting material block. The nitrogen content was within $80 \mathrm{ppm}$ and measured as $<21 \mathrm{ppm}$. 
Question from Linhua Chu, State Nuclear Baoti Zirconium Industry Company:What is the link between the experimental results and the finite element model? In other words, how can you prove the FE model you used in the work is correct?

We use the force-displacement curves from the experiment and FE model to test/verify the accuracy of the FE model.

Authors' Response:-The FE analysis is somewhat limited by the lack of detailed knowledge of the temperature field; hence, the analysis assumes a realistic worst-case upper bound as a proof of concept. Reproduction of the sample barreling goes some way toward verifying the FE model (shown by comparison of the sample sections in fig. 8 and in the heat map in fig. 9). Given the experimental limitations on the modeling, it is not possible to generate definitive corrected stressstrain data. However, we clearly demonstrate the order of corrections to the flow stress curves that can be needed (fig. 6), and-importantly-that the strain-rate sensitivity inferred from the raw experimental flow stress curves may deviate significantly from the true strain-rate sensitivity of the material (fig. 10) because the offset correction was found to vary with strain and at the different test conditions.

Questions from Rick Holt, Queen's University:

1. How were the ends of the specimens lubricated to prevent barreling?

2. In the actual manufacturing process, there is a wide range of strain rates. How would DMM theory be applied in this case?

\section{Authors' Response:}

1. We lubricated the ends of the samples with a nickel-graphite paste to reduce friction in these tests. Molybdenum discs can also be placed on the ends of the sample to reduce the temperature inhomogeneity and friction.

2. This question highlights another limitation of the processing map method and DMM theory for industrial application. As mentioned previously, we do not recommend any particular "idealized" regime within the processing map, as suggested in other such studies. However, we do find a gradual increase in strain-rate sensitivity at lower strain rates and higher temperatures, which could be used to tailor the manufacturing process. With careful application of the FE model, using corrections to the flow stress, we find a range of deformation conditions develop across each of the compression specimens, meaning it is possible to examine a range of different microstructures and relate them to exact process conditions. We believe this type of systematic examination, in combination with the FE model, would be more revealing and transparent than using DMM theory to produce processing maps. 
Question from Bruce Kammenzind, Naval Nuclear Labs:-Your temperature range processing is in the middle of the two-phase field for $\mathrm{Zr}-2.5 \mathrm{Nb}$ alloys, which can also be affected by impurity contents. Is there an optimal alpha/beta phase fraction for processing and what was the oxygen content of the material used in the study?

Authors' Response:-The oxygen content of the starting material is mentioned in an earlier question and was carefully controlled during production, along with the impurity contents.

The final processing map, produced after correcting the flow stress using the FE model, is not particularly revealing about an optimal processing temperature, except to show that strain-rate sensitivity increases at higher temperatures. The change in processing temperature also changes the $\alpha / \beta$ volume fraction, which can dramatically alter the crystallographic texture. We would recommend using final texture to guide any optimization of processing temperature because texture has a significant effect on the in-reactor performance and service lifetime. Our recent study investigates the effect of incremental changes in the processing temperature and the effect on final texture, which was shown as a poster at the latest symposium. The results have also been published in our paper. ${ }^{1}$

1. C. S. Daniel, P. D. Honniball, L. Bradley, M. Preuss, and J. Quinta da Fonseca, "A Detailed Study of Texture Changes during Alpha-Beta Processing of a Zirconium Alloy," Journal of Alloys and Compounds 804 (2019): 65-83. 